\title{
Resolving chemical and spatial heterogeneities at complex electrochemical interfaces in $\mathrm{Li}$ ion batteries
}

1 Julia C. Hestenes ${ }^{1}$, Richard May ${ }^{2}$, Jerzy T. Sadowski ${ }^{3}$, Naiara Munich ${ }^{4}$, Lauren E. Marbella ${ }^{2 *}$

$2 \quad{ }^{1}$ Department of Applied Physics and Applied Mathematics, Columbia University, New York, New

3 York 10027

$4 \quad{ }^{2}$ Department of Chemical Engineering, Columbia University, New York, New York 10027

$5 \quad{ }^{3}$ Center for Functional Nanomaterials, Brookhaven National Laboratory, Upton, New York 11973

$6 \quad{ }^{4}$ Department of Chemistry, Barnard College of Columbia University, New York, New York 10027

7 *Correspondence:

8 Lauren E. Marbella

9 lem2221@columbia.edu

10 Keywords: Li-ion battery, cathode electrolyte interphase (CEI), NMC811, surface chemistry, 11 spatial arrangement, in situ NMR spectroscopy, XPEEM

\section{Abstract}

The high specific capacities of Ni-rich transition metal oxides have garnered immense interest for improving the energy density of Li-ion batteries (LIBs). Despite the potential of these materials, Ni-rich cathodes suffer from interfacial instabilities that lead to crystallographic rearrangement of the active material surface as well as the formation of a cathode electrolyte interphase (CEI) layer on the composite during electrochemical cycling. While changes in crystallographic structure can be detected with diffraction-based methods, probing the chemistry of the disordered, heterogeneous CEI layer is challenging. In this work, we use a combination of ex situ solid-state nuclear magnetic resonance (SSNMR) spectroscopy and X-ray photoemission electron microscopy (XPEEM) to provide chemical and spatial information on the CEI deposited on $\mathrm{LiNi}_{0.8} \mathrm{Mn}_{0.1} \mathrm{Co}_{0.1} \mathrm{O}_{2}$ (NMC811) composite cathode films. Specifically, XPEEM elemental maps offer insight into the lateral arrangement of the electrolyte decomposition products that comprise the CEI and paramagnetic interactions (assessed with electron paramagnetic resonance (EPR) and relaxation measurements) in ${ }^{13} \mathrm{C}$ SSNMR provide information on the radial arrangement of the CEI from the NMC811 particles outward. Using this approach, we find that $\mathrm{LiF}, \mathrm{Li}_{2} \mathrm{CO}_{3}$, and carboxy-containing structures are directly appended to NMC811 active particles, whereas soluble species detected during in situ ${ }^{1} \mathrm{H}$ and ${ }^{19} \mathrm{~F}$ solution NMR experiments (e.g., alkyl carbonates, HF, and vinyl compounds) are randomly deposited on the composite surface. We show that the combined approach of ex situ SSNMR and XPEEM, in conjunction with in situ solution NMR, allows spatially-resolved, molecular-level characterization of paramagnetic surfaces and new insights into electrolyte oxidation mechanisms in porous electrode films.

\section{Introduction}

Ni-rich cathode materials offer high energy densities $(>200 \mathrm{mAh} / \mathrm{g})^{1,2}$ while simultaneously reducing the amount of costly $\mathrm{Co}^{3}$ used in Li-ion batteries (LIBs). Despite these advantages, Ni-rich cathodes, such as $\mathrm{LiNi}_{0.8} \mathrm{Mn}_{0.1} \mathrm{Co}_{0.1} \mathrm{O}_{2}$ (abbreviated NMC811), suffer from severe thermal ${ }^{1}$ and 
interfacial ${ }^{2,4,5}$ instabilities during usage that prevent broad application. Degradation pathways in NMC811 cathodes include particle cracking, ${ }^{5-8}$ gas evolution, ${ }^{9-11}$ surface reconstruction, ${ }^{12-14}$ transition metal dissolution, ${ }^{5,15-17}$ and parasitic interfacial reactions with the electrolyte ${ }^{4,18,19}$-many of which are strongly coupled to one another. Changes in the crystallographic and secondary particle structure of Ni-rich NMCs are readily identified using diffraction- and imaging-based techniques. ${ }^{12,13,20-24}$ For example, X-ray tomography and electron microscopy can detect crack formation in NMC secondary particles during electrochemical cycling. ${ }^{6,25}$ Electrolyte molecules can then infiltrate these cracks and participate in side reactions that lead to poor capacity retention. ${ }^{5}$ Electron and X-ray diffraction measurements indicate that repeated cycling of NMC811 leads to oxygen depletion at the particle surface, forming a $\mathrm{NiO}$ reconstruction layer that blocks $\mathrm{Li}^{+}$transport ${ }^{12}$ and increases the charge-transfer resistance. $^{26}$ The associated oxygen evolution can be directly quantified using differential/on-line electrochemical mass spectrometry (DEMS/OEMS). ${ }^{27-29}$ Strongly oxidizing species generated during battery operation, such as molecular oxygen and freshly exposed $\mathrm{Ni}^{4+} / \mathrm{Ni}-\mathrm{O}$ sites, ${ }^{30-32,4,33}$ can then go on to attack the electrolyte, leading to further performance degradation. The resulting electrolyte decomposition products deposit on the cathode surface, leading to a disordered, multiphase cathode electrolyte interphase $(\mathrm{CEI})^{34}$ layer that alters Li transport to the active material.

Unfortunately, characterizing the composition and the arrangement of the CEI layer, and correlating these features with battery performance, is exceptionally challenging due to the complexity of composite cathode films. The cathodes used in technologically-relevant LIBs contain active particles (e.g., NMC811) embedded in a heterogeneous matrix of conductive carbon and polyvinylidene fluoride (PVDF) binder, presenting issues with both chemical and spatial resolution in CEI characterization. ${ }^{35-}$ 37 High chemical resolution is essential to distinguishing signals that arise from electrolyte decomposition products versus carbon additives in the composite. Both the CEI layer and the carbon additives are highly disordered and contain light elements $(\mathrm{H}, \mathrm{C}, \mathrm{F})$ that are difficult to resolve with traditional surface science methods. Li salts and solvents from the electrolyte can get trapped in the porous cathode composite, leading to signal overlap with potential electrolyte decomposition products. In addition, spatial resolution in CEI characterization (e.g., measuring the location of electrolyte decomposition products as they deposit on the heterogenous cathode composite) is important for determining the reactivity associated with the active particle versus the carbon additives. For example, a recent study suggested that surface $\mathrm{Ni}-\mathrm{O}$ sites attack cyclic ethylene carbonate (EC) solvent, appending dehydrogenated EC molecules to the NMC811 surface. ${ }^{18,33}$ Direct attachment of electrolyte decomposition products to the active particle is consistent with work from Gasteiger and coworkers that shows high surface area carbons do not evolve $\mathrm{CO}_{2}$ (from EC ring opening) in the absence of NMC particles. ${ }^{36}$ While these reports strongly suggest that electrolyte oxidation occurs at the active particle surface, no direct evidence for CEI attachment at the active material was obtained. In contrast, several reports have identified electrolyte decomposition products on the carbon additives, ${ }^{35,38,39}$ but it is not clear if these species decompose directly on the carbon/binder or if they are deposited on the composite in some other fashion (e.g., during anode/cathode crosstalk).

Nuclear magnetic resonance (NMR) spectroscopy is a powerful, non-destructive tool to characterize electrochemical interfaces in their native operating environment. The high chemical resolution, especially for light elements (e.g., ${ }^{13} \mathrm{C}$ ), can be leveraged to determine the precise molecular structure of electrolyte decomposition products present in interphase layers. While solid-state NMR (SSNMR) has been used to characterize the composition of the electrode/electrolyte interphase (EEI) on the anode side of the battery, ${ }^{40-45}$ substantially less work has focused on using SSNMR to characterize the CEI on the cathode. ${ }^{46-49}$ Most industrially-relevant cathode materials contain paramagnetic transition metals (e.g., Co, Mn, Ni, Fe). ${ }^{50,51}$ Unpaired electrons from these paramagnetic substrates can couple to nuclei in the CEI layer, leading to fast nuclear spin relaxation and severe line

This is a provisional file, not the final typeset article 
83 broadening during NMR characterization ${ }^{50,52,53}$ which presents a technical challenge for detecting 84 discrete compounds in the CEI with NMR. Traditional signal enhancement strategies used in SSNMR, such as ${ }^{1} \mathrm{H} \rightarrow{ }^{13} \mathrm{C}$ cross polarization magic-angle spinning (CPMAS), do not work on paramagnetic cathodes due to fast relaxation during the CP step of the NMR experiment, ${ }^{54}$ further hindering CEI characterization efforts.

Here, we show that by manipulating the Ni oxidation state in NMC811 cathode composites, we can determine the composition and arrangement of the CEI using SSNMR. We report that direct polarization of ${ }^{13} \mathrm{C}$ nuclei in SSNMR facilitates detection and compositional assignment of the CEI formed on NMC811 upon delithiation (charging of the battery). Electron paramagnetic resonance (EPR) spectroscopy indicates that during battery charging, oxidation of $\mathrm{Ni}^{2+}$ to $\mathrm{Ni}^{4+}$ dilutes the paramagnetic matrix present in NMC811, greatly decreasing the magnetic susceptibility and enabling well-resolved SSNMR of organic species in the CEI. In particular, we show that carbonates directly bound to NMC particles can be discerned from CEI species spatially distant from NMC with SSNMR because NMC-bound carbonates produce a characteristic spinning sideband pattern in the NMR spectrum. These data indicate that SSNMR provides radial information (as measured from the center of the NMC particle) on CEI arrangement, where compounds closest to the NMC811 active particles exhibit spinning sidebands. SSNMR measurements are complemented with X-ray photoemission electron microscopy (XPEEM) elemental imaging experiments, which reveal the lateral arrangement of $\mathrm{LiF}$ and the organic decomposition products in the CEI of the composite cathode film. While LiF and carboxy-containing $\mathrm{Li}$ salts and $\mathrm{Li}_{2} \mathrm{CO}_{3}$ selectively deposit on NMC811 particles, alkyl carbonates are randomly distributed on the composite (i.e., indiscriminately on the active material and the carbon additives), possibly due to their more soluble nature and/or anode/cathode crosstalk. Soluble electrolyte oxidation products (e.g., short-chain alkyl carbonates, vinyl species, and HF) from side reactions at the NMC surface are identified with ex situ and in situ solution NMR spectroscopy, allowing us to rationalize the distribution of organic small molecules in the CEI.

\section{Materials and Methods}

\section{Materials.}

Li metal ribbon (0.75 mm thick), $1 \mathrm{M} \mathrm{LiPF}_{6}$ in ethylene carbonate:dimethyl carbonate (EC:DMC 1:1 v/v, LP30, battery grade), 1-methyl-2-pyrrolidinone (NMP, anhydrous, 99.5\%), KBr ( $\geq 99.0 \%)$, silica gel (ultrapure, $60-200 \mu \mathrm{m})$ and Au powder ( $\geq 99.9 \%$, particle size $\leq 10 \mu \mathrm{m}$ ) were purchased from Sigma-Aldrich. DMSO- $d_{6}(\geq 99.9 \%)$ was purchased from Cambridge Isotope Laboratories. Prior to use, DMSO- $d_{6}$ was dried over molecular sieves in an Ar-filled glovebox $\left(\mathrm{O}_{2}<0.1 \mathrm{ppm}, \mathrm{H}_{2} \mathrm{O}<0.5 \mathrm{ppm}\right)$ for $48 \mathrm{~h}$. Both $\mathrm{KBr}$ and the silica gel were dried at $60{ }^{\circ} \mathrm{C}$ for 7 days before bringing into the glovebox for preparation of SSNMR samples. The surface oxide layer on Li metal was scraped off prior to assembly in Li/NMC half cells. All other chemicals were used as received. NMC811, NMC532, and NMC111 cathode powders were purchased from MTI Corporation. All cathode powders were stored in an Ar-filled glovebox. Carbon super P C45 and PVDF were purchased from MTI Corporation and used as received.

\section{Electrode Fabrication}

Cathode films for each NMC composition were prepared by first hand grinding a 10:1 ratio (by mass) of NMC: carbon super P. This mixture was added to a solution of PVDF binder in NMP at a 10:1 ratio (by mass) of $\mathrm{NMC}+\mathrm{C}: \mathrm{PVDF}$ to create a viscous slurry. The slurry was cast onto an $\mathrm{Al}$ current collector $\left(25 \mu \mathrm{m}\right.$ thick, MTI Corporation) using a $150 \mu \mathrm{m}$ doctor blade and dried at $100{ }^{\circ} \mathrm{C}$ under vacuum overnight. The dried film was punched into $12.7 \mathrm{~mm}$ diameter disks to use in cell assembly. 
127 Once dried, cathode films were stored in an Ar-filled glovebox to minimize exposure to air and

128 moisture. Typical mass loadings of active material (e.g., NMC811) per cathode were $8-13 \mathrm{mg} \mathrm{cm}^{-2}$. 129 These electrodes were used for all electrochemical testing, and then extracted for EPR, NMR or 130 XPEEM characterization.

\section{Electrochemistry}

\section{Solid-State NMR Spectroscopy}

SSNMR experiments were performed at room temperature on a Bruker Avance NEO $600 \mathrm{MHz}$ spectrometer equipped with a $1.6 \mathrm{~mm}$ HFXY MAS Phoenix NMR probehead. To prepare samples for SSNMR, Li/NMC half cells were disassembled in the glovebox at the desired state of charge (e.g., at the end of charge at $4.6 \mathrm{~V}$ ). After cell disassembly, the cathode film was scraped from the Al current collector and dried under vacuum overnight to remove residual solvent. Electrodes were not washed during sample preparation to preserve the highly sensitive interphase layer. Each sample was mixed with $\mathrm{KBr}$ powder or silica gel in a roughly 1:1 ratio by mass in a mortar and pestle until homogenized to fill a $1.6 \mathrm{~mm}$ o.d. $\mathrm{ZrO}_{2}$ rotor. All experiments were performed at $28 \mathrm{kHz}$ MAS frequency, unless otherwise noted. ${ }^{1} \mathrm{H}$ and ${ }^{13} \mathrm{C}$ spin echo spectra were collected using a rotor-synchronized spin echo pulse sequence $\left(90^{\circ}-\tau-180^{\circ}-\tau\right.$-acquire, with $\tau$ set to 1 rotor period) with a recycle delay of $10 \mathrm{~s}$ and $0.8 \mathrm{~s}$, respectively. While direct polarization of ${ }^{13} \mathrm{C}$ SSNMR of diamagnetic samples often requires long acquisition times, fast $T_{1}$ relaxation of the CEI on the paramagnetic cathode let us to acquire ${ }^{13} \mathrm{C}$ SSNMR more quickly by using a short recycle delay of $0.8 \mathrm{~s}$ (recycle days were varied from 0.8-10 s to determine the optimal value). For ${ }^{13} \mathrm{C}$ SSNMR, ${ }^{1} \mathrm{H}$ decoupling was performed with TPPM at $\sim 100$ kHz. ${ }^{1} \mathrm{H} T_{1}$ measurements of the CEI on NMC811 (Table S1), show that relaxation of ${ }^{1} \mathrm{H}$ nuclei present on NMC811 composites is too short (on the order of ms) to perform CPMAS experiments (the contact pulse is typically applied for ms). ${ }^{13} \mathrm{C}$ SSNMR spectra presented in this study were acquired over a period of about $14-18 \mathrm{~h}$ per sample, equivalent to $\sim 100,000$ scans per sample. Single pulse ${ }^{7} \mathrm{Li} S \mathrm{SNMR}$ spectra were collected using $90^{\circ}$ pulse length of $2.6 \mu \mathrm{s}, 5$ s recycle delay, and 128 scans. All SSNMR spectra presented are normalized to the maximum peak height in the given spectrum, unless otherwise noted. ${ }^{1} \mathrm{H}$ NMR was externally referenced to adamantane at $1.85 \mathrm{ppm} .{ }^{13} \mathrm{C} \mathrm{NMR}$ was externally referenced to the high frequency peak of adamantane at $38.5 \mathrm{ppm} .{ }^{7} \mathrm{Li} \mathrm{NMR}$ was externally referenced to $\mathrm{LiF}$ at $-1 \mathrm{ppm}$ or $\mathrm{Li}_{2} \mathrm{CO}_{3}$ at $0 \mathrm{ppm}$. We attempted to collect ${ }^{19} \mathrm{~F} \mathrm{SSNMR}$ from these samples, but no signals from common electrolyte decomposition products (e.g., $\mathrm{LiF}$ at $-204 \mathrm{ppm}$ ) were observed, likely due to the higher gyromagnetic ratio of ${ }^{19} \mathrm{~F}$ compared to ${ }^{13} \mathrm{C}\left(\gamma_{19 \mathrm{~F}}=2.52 \times 10^{8} \mathrm{rad} / \mathrm{sT}\right.$ compared to $\gamma_{13 \mathrm{C}}$ $=6.73 \times 10^{7} \mathrm{rad} / \mathrm{sT}$ ) and the close proximity to the NMC811 surface. 
X-band EPR measurements were performed on an ESR-5000 spectrometer manufactured by Freiberg Instruments for Bruker, sold by Rotunda Scientific Technologies. The spectrometer has a microwave frequency of $9.47 \mathrm{GHz}$ at room temperature. All measurements employed a $B$-field sweep from 50 to $650 \mathrm{mT}$, microwave power of $0.3162 \mathrm{~W}, 0.5 \mathrm{mT}$ modulation amplitude with $100 \mathrm{kHz}$ frequency, and a $60 \mathrm{~s}$ sweep time with 1 scan. Dried cathode samples extracted from $\mathrm{Li} / \mathrm{NMC}$ half cells were ground with $\mathrm{KBr}$ and packed into either a Bruker $1.9 \mathrm{~mm}$ or Varian $1.6 \mathrm{~mm} \mathrm{ZrO}_{2}$ rotor. The rotor was placed into a quartz EPR tube for measurement. Because the content of carbon was kept constant in the cathodes and is not electrochemically active (10 wt\% of the composite film), spectra are normalized to the peak from conductive carbon.

\section{8}

179

180

\section{XPEEM}

Prior to electrochemical cycling, NMC811 cathodes were prepared by pressing composite cathode films at 2 tons in a hydraulic press (Specac) to flatten the sample for XPEEM. After cycling, cathode films were removed from the batteries in the glovebox and dipped into $1 \mathrm{~mL}$ DMC twice for $3 \mathrm{~s}$ each to remove residual salts and minimize surface layer outgassing in the vacuum chamber. Cathode films were then dried under vacuum overnight to removal residual solvent. Samples were double sealed in airtight pouches under Ar and transferred to the XPEEM facility at Brookhaven National Laboratory (BNL) for measurement. Samples were mounted on XPEEM holders in an Arfilled glovebox and transferred to the XPEEM vacuum chamber using an air-free suitcase.

Pixel-wise X-ray absorption spectra (XAS) were obtained by recording a series of XPEEM images at each energy in a given absorption edge range at sequential increments of $0.2 \mathrm{eV}$. Ni L-edge spectra were referenced to the low energy $\mathrm{L}_{3}$ edge peak, which has a reported value of $853.5 \mathrm{eV} .{ }^{55}$ Other edges were translated accordingly, except the C K-edge which referenced the lowest energy peak, assigned to conductive carbon, at $285.4 \mathrm{eV} .{ }^{37,56}$ Local XAS spectra can be extracted by plotting the intensity of a given spatial region (set of pixels) at each energy. For example, for Ni L-edge, 152 XPEEM images were acquired from $850 \mathrm{eV}-880 \mathrm{eV}$. XPEEM elemental contrast images were obtained by subtracting the pre-edge image from the desired X-ray absorption energy. The $\mathrm{C}$ K-edge image at $292.8 \mathrm{eV}$ was extracted to display the spatial distribution of conductive carbon. The pre-edge image at $280.0 \mathrm{eV}$ was then subtracted, yielding the final elemental map of conductive carbon. The same procedure was conducted for other elements presented in these elemental maps: Ni L-edge at $853.5 \mathrm{eV}$ for $\mathrm{Ni}^{2+/ 3+}$ and $855.9 \mathrm{eV}$ for $\mathrm{Ni}^{4+}(850.0 \mathrm{eV}$ pre-edge subtracted), and $\mathrm{F} \mathrm{K}$-edge at $691.7 \mathrm{eV}$ for PVDF (685.0 eV pre-edge subtracted).

Acquisition of C K-edge spectra in XPEEM is challenging due to strong absorption at this edge from carbon impurities in the X-ray optics as well as the Au mesh typically used to normalize the spectra of absorption edges of other elements. ${ }^{37}$ To make use of these spectra, we adopted the approach reported by El-Kazzi and coworkers ${ }^{37}$ where Au microparticles are deposited on a small portion of the surface of a pristine NMC811 film for internal referencing prior to pressing the sample at 2 tons. Local $\mathrm{C}$ K-edge spectrum at the Au particle was extracted and used to normalize all other local C K-edge spectra from the cathode films to yield the true C K-edge spectrum. ${ }^{37}$ Each spectrum presented was normalized to a maximum intensity of one unless otherwise noted.

\section{Ex and In Situ Solution NMR}

For ex situ solution NMR measurements, Li/NMC811 half coin cells were disassembled in the glovebox after cycling. The glass fiber separator was soaked in $1 \mathrm{~mL} \mathrm{DMSO-} d_{6}$ for $5 \mathrm{~min}$ and compressed using clean tweezers to fully extract electrolyte from the separator. The resulting solution was pipetted into a $5 \mathrm{~mm}$ air-tight J-Young NMR tube for analysis. All solution NMR experiments were performed on a Bruker Avance III 400 spectrometer equipped with a triple resonance broadband 
214 observe (TBO) probehead. One-dimensional (1D) ${ }^{1} \mathrm{H}\left(30^{\circ}\right.$ single pulse, $1 \mathrm{~s}$ recycle delay, 16 scans, 215 internally referenced to residual DMSO at $2.5 \mathrm{ppm})$ and ${ }^{19} \mathrm{~F}\left(30^{\circ}\right.$ single pulse, 2 s recycle delay, 32 216 scans, internally referenced to $\mathrm{PF}_{6}{ }^{-}$at $-74.5 \mathrm{ppm}$ ) were recorded at room temperature. Three replicate samples were measured.

For in situ solution NMR measurements, we designed a Li/NMC811 tube cell to collect ${ }^{1} \mathrm{H}$ and ${ }^{19} \mathrm{~F}$ NMR during electrochemical cycling. The Li/NMC811 cell was galvanostatically cycled for 10 cycles and placed in the NMR magnet for measurement. This method eliminates the need to disassemble the working cell for NMR and expose electrolyte decomposition products to DMSO- $d_{6}$ NMR solvent for locking. The in situ cell was assembled as a flood cell in a chemically resistant FEP NMR tube liner with o.d. $=3.65 \mathrm{~mm}$ and i.d. $=3.15 \mathrm{~mm}$ that was purchased from Wilmad Glassware. A NMC811/C45/PVDF/NMP cathode slurry was cast on an Al substrate and dried overnight in vacuo. Once dried, a $2.5 \mathrm{~mm}$ wide $\times 22 \mathrm{~cm}$ long section was cut out of the film such that only the bottom $\sim 2$ $\mathrm{cm}$ was covered with the NMC811 composite. This method allows for the Al substrate to serve as both a current collector for the NMC and lead for electrochemical connection, similar to the approach reported by Nowak and coworkers. ${ }^{57}$ Active material loading was estimated such that the first cycle was consistent with $\mathrm{C} / 10$ cycling ( 1-2 $\mathrm{mg}$ ). For the anode, a $2 \mathrm{~mm}$ wide $\times 2 \mathrm{~cm}$ long piece of Li was hammered onto $\mathrm{Cu}$ mesh. The $\mathrm{Cu}$ mesh was connected to a $22 \mathrm{~cm}$ long pure $\mathrm{Cu}$ wire via a heat-shrink, chemically resistant electrical insulation tubing. The heat-shrink tubing prevented cell shorting along the length of the NMR tube. The Li metal was wrapped in a single layer of Celgard 2325 separator. Prior to electrode insertion, $300 \mu \mathrm{L}$ of LP30 was pipetted into the tube liner. Electrodes were inserted into the tube such that the ends are $25 \mathrm{~mm}$ from the bottom of the FEP tube. It is important that the electrodes remain outside the receiver coil (coil length $23.85 \mathrm{~mm}$ ) during NMR measurement to be able to obtain a high quality shim for satisfactory resolution in ${ }^{1} \mathrm{H}$ NMR. The cell was cycled for 10 full cycles at $\mathrm{C} / 10$ between 3.0-4.6 V. After cycling, the tube cell was disconnected, submerged into a $5 \mathrm{~mm}$ glass NMR tube containing $0.1 \mathrm{~mL}$ DMSO- $d_{6}$ and immediately brought to the spectrometer for measurement of the electrolyte contents. NMR acquisition parameters are the same as described above for $e x$ situ solution NMR, except 64 scans were used for ${ }^{19} \mathrm{~F}$ acquisition. The high sensitivity of ${ }^{1} \mathrm{H}$ and ${ }^{19} \mathrm{~F}$ NMR allowed us to collect spectra in less than $3 \mathrm{~min}$. Low concentration ${ }^{1} \mathrm{H}$ species with chemical shifts between 2.5 ppm-5.5 ppm cannot be discerned with this method since this region is dominated by the electrolyte solvent signals (the bulk component of the sample, Figure S15).

\section{Background/Theory}

In paramagnetic systems, unpaired electrons can interact with nearby nuclei, leading to fast nuclear relaxation behavior. These interactions scale with the magnetic moment of the paramagnet, the electron-nuclear interspin distance $\left(r^{-3}\right)$, and gyromagnetic ratio $(\gamma)$ of the observe nucleus. ${ }^{51,54}$ As a result, nuclear coupling with electronic spins is strongest when in close proximity to unpaired electrons and increases for high $\gamma$ nuclei (e.g., ${ }^{1} \mathrm{H},{ }^{19} \mathrm{~F}$ ) compared to low $\gamma$ nuclei (e.g., ${ }^{13} \mathrm{C}$ ). In SSNMR, two nuclear relaxation processes influence the resulting SSNMR signal acquisition: spin-lattice $\left(T_{1}\right)$ and spin-spin $\left(T_{2}\right)$ relaxation times, both of which typically decrease when near unpaired electrons. $T_{1}$ relaxation describes the time it takes for the spin system to reach thermal equilibrium in the external magnetic field, $B_{0}$. Thus, the $T_{1}$ time determines how long one must wait between individual NMR measurements during signal averaging. In paramagnetic systems, $T_{1}$ is typically very fast (on the timescale of ms), allowing fast interscan repetition (i.e., recycle delays) that lead to short NMR experiment times. $T_{2}$ relaxation is inversely proportional to the full width at half maximum (fwhm) of the resulting NMR signal. $T_{2}$ values are also very short in paramagnetic systems (on the order of $\mu \mathrm{s}$ ), ${ }^{58}$ leading to broad NMR lineshapes compared to diamagnetic compounds. In magic-angle spinning (MAS) SSNMR experiments, these broad lineshapes are broken up into a spinning sideband pattern (often denoted with asterisks) that envelopes the peak breadth observed under static conditions. Each 
spinning sideband is separated by the MAS frequency. The isotropic resonance is invariant of the spinning frequency and is used in NMR to assign chemical environments, akin to the isotropic resonance observed in solution NMR. Consequently, as the MAS frequency changes, the isotropic resonance remains constant, while the separation between individual sidebands changes.

Prior work from our group on $\mathrm{Li}_{2} \mathrm{RuO}_{3}$ model cathodes indicates that quenching paramagnetism in the active material facilitates SSNMR characterization of the CEI layer generated during electrochemical cycling of layered transition metal oxide cathodes. ${ }^{46}$ In this work, we hypothesize that oxidation of paramagnetic $\mathrm{Ni}^{2+/ 3+}$ to diamagnetic $\mathrm{Ni}^{4+}$ in NMC811 composite films will similarly reduce the magnetic susceptibility and the resulting electron-nuclear coupling between the substrate (NMC) and the CEI layer, allowing for acquisition of high resolution SSNMR of the CEI. To test this hypothesis, we can (i) directly monitor changes in paramagnetism of the composite and (ii) measure changes in nuclear spin relaxation in the CEI as a function Ni oxidation state. In the first instance, changes in the magnetic properties of NMC811 during lithiation/delithiation are measured with EPR spectroscopy, which is sensitive to the presence of paramagnetic centers and their exchange interactions. ${ }^{59}$ The area under the EPR curve represents the number of unpaired electrons in the sample, which is proportional to the magnetic susceptibility of the sample. In the second case, weakened paramagnetism of the composite cathode substrate upon delithiation is expected to increase the $T_{1}$ and $T_{2}$ relaxation times of the appended CEI layer, where longer relaxation times are expected to mitigate paramagnetic line broadening and the associated poor chemical resolution in SSNMR. In contrast, lithiation (discharge) of NMC811 is expected to increase paramagnetic interactions between the substrate and the CEI, leading to signal dephasing in SSNMR. Accordingly, both EPR spectroscopy of the bulk NMC as well as $T_{1}$ measurements of the

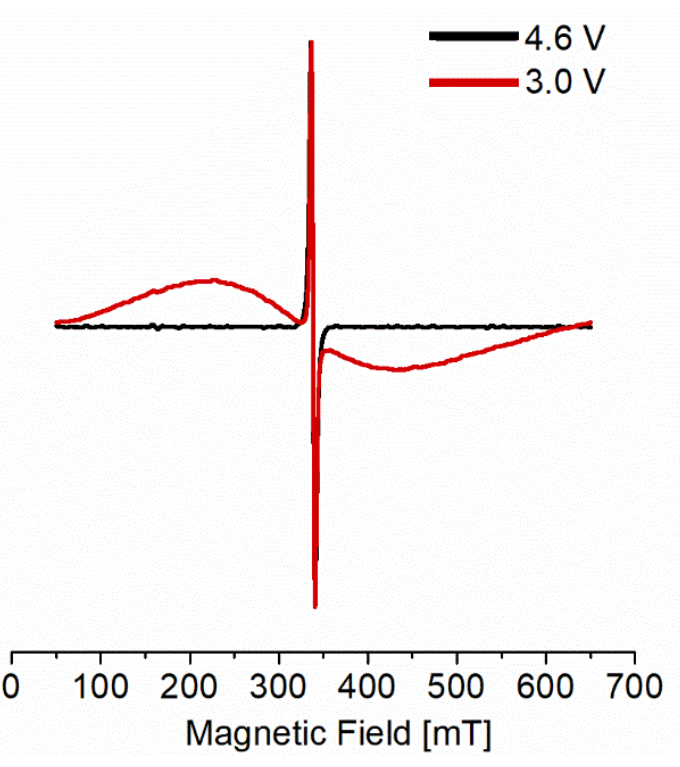

Figure 1. X-band EPR spectra of NMC811 composites after the first charge at $\mathrm{C} / 10$ to 4.6 $\mathrm{V}$ vs $\mathrm{Li} / \mathrm{Li}^{+}$(black line) and the corresponding discharge to $3.0 \mathrm{~V}$ vs $\mathrm{Li} / \mathrm{Li}^{+}$ (red line). The sharp peaks in the center of the spectra correspond to conductive carbon in the composite, whereas the broad lineshape observed upon discharge is assigned to NMC811.
CEI as a function of NMC811 charge state are presented in the following section.

\section{Results}

To provide context for the SSNMR measurements of the CEI on NMC811, we start by investigating the magnetic properties of composite cathode films at different states-of-charge (SoC) and different number of cycles. Figure 1 shows the EPR spectra of NMC811:C:PVDF (80:10:10) composites obtained after discharging $\left(3.0 \mathrm{~V}\right.$ vs $\mathrm{Li} / \mathrm{Li}^{+}$, red $)$and charging (4.6 V vs $\mathrm{Li} / \mathrm{Li}^{+}$, black) in $\mathrm{Li}$ half cells. Upon discharge to $3.0 \mathrm{~V}$ at the end of the first cycle, we observe a narrow resonance that is characteristic of unpaired electrons in the conductive carbon ${ }^{60,61}$ as well as a broad resonance from the network of paramagnetic transition metal cations in NMC $811 .{ }^{59} \mathrm{We}$ expect that the formal oxidation states in NMC811 are $\mathrm{LiNi}^{2+}{ }_{0.1} \mathrm{Ni}^{3+}{ }_{0.7} \mathrm{Mn}^{4+}{ }_{0.1} \mathrm{Co}^{3+} \mathrm{O}_{2},{ }^{62,63}$ where the paramagnetic centers in the material include $\mathrm{Ni}^{3+}(S$ $=1 / 2), \mathrm{Ni}^{2+}(S=1)$, and $\mathrm{Mn}^{4+}(S=3 / 2) \cdot \mathrm{Co}^{3+}(S=0)$ is diamagnetic and thus, EPR inactive. ${ }^{64,65}$ Therefore, we assign the broad signal observed at $3.0 \mathrm{~V}$ to $\mathrm{Mn}^{4+}-\mathrm{Ni}^{2+}$ exchange coupling interactions 
307 in the active material, ${ }^{61,64-68}$ which is supported by control experiments comparing NMC811 with 308 NMC532, NMC111, and LNMO ( $\left.\mathrm{LiNi}_{0.5} \mathrm{Mn}_{1.5} \mathrm{O}_{4}\right)$ (Figures S1-S2).

Upon charging to $4.6 \mathrm{~V}$ in the first cycle, the EPR signal from NMC811 is quenched, while the 310 signal from conductive carbon is still present (Figure 1). The persistence of the EPR signal from 311 conductive carbon is expected because the carbon additives are not electrochemically active. Decreased 312 EPR signal from the active material in the cathode composite is consistent with the oxidation of $313 \mathrm{Ni}^{2+} / \mathrm{Ni}^{3+}$ (paramagnetic) to $\mathrm{Ni}^{4+}\left(S=0\right.$, diamagnetic) that occurs during delithiation. ${ }^{22,65,66}$ Since the $314 \mathrm{Mn}^{4+}(S=3 / 2)$ and $\mathrm{Co}^{3+}(S=0)$ are not redox active, ${ }^{31,69,70}$ the EPR signal from NMC811 disappears 315 as the bulk oxidation state of the transition metal centers are oxidized to form diamagnetic $\mathrm{Ni}^{4+}$. 316 Paramagnetic $\mathrm{Mn}^{4+}$ cannot couple with diamagnetic $\mathrm{Ni}^{4+}$, decreasing the observable EPR signal. ${ }^{61}$ The gradual decay in EPR upon charging NMC811 composites is shown in Figure S3, where the EPR signal disappears at voltages $\geq 4.2 \mathrm{~V}$, indicating that the net magnetic susceptibility of the bulk sample decreases with increasing SoC.

A very low intensity, broad EPR signal, reminiscent of the active material at discharge, appears after 50 galvanostatic cycles in the charged state (Figure S4) that likely corresponds to surface reconstruction after repeated lithiation/delithiation. Terminal $\mathrm{Ni}^{4+}$ sites on the surface of NMC811 are highly unstable, and are reduced to form a $\mathrm{Ni}^{2+}-\mathrm{O}$ rocksalt layer that has been widely reported in the literature ${ }^{12,13,31,55,71-73}$ and can be visualized in XPEEM maps (see below, Figure 3). The $\mathrm{Ni}^{2+}$ on the active particle surface can undergo exchange coupling with neighboring $\mathrm{Mn}^{4+}$ sites, leading to the low intensity, exchange-narrowed EPR spectrum. The NiO layer represents a small proportion of the overall sample and based on the EPR intensities, we conclude that even after 50 cycles, the magnetic susceptibility of the substrate is substantially smaller than that observed upon discharge. Strong paramagnetism at discharge and weaker paramagnetism at charge is also supported by ${ }^{1} \mathrm{H} T_{1}$ relaxation measurements of the corresponding CEI layer. For example, ${ }^{1} \mathrm{H} T_{1}$ values for the CEI on NMC811 composites upon charging to $4.6 \mathrm{~V}$ are two orders of magnitude greater than that observed upon discharge (Table S1, Figure S5), and thus, charged Ni-rich cathode samples are expected to produce better-resolved NMR spectra for CEI detection. However, the $T_{1}$ of NMC at charge is still relatively 
334 fast $\left(10^{-1} \mathrm{~s}\right)$ compared to diamagnetic materials due to weak paramagnetism associated with residual 335 (but dilute) paramagnetic centers such as $\mathrm{Mn}^{4+}, \mathrm{Ni}^{3+/ 2+}$ from incomplete delithiation and surface $\mathrm{NiO}$.

With an understanding of the paramagnetic properties of NMC811 composites in hand, we next use ${ }^{13} \mathrm{C}$ SSNMR to characterize the organic CEI that forms after 50 galvanostatic cycles when cells are disassembled at $4.6 \mathrm{~V}$, where the paramagnetism is the lowest (Figure 2a). Representative voltage profiles collected during the $1^{\text {st }}$ and $50^{\text {th }}$ cycle of Li/NMC811 half cells is shown in Figure S6. As
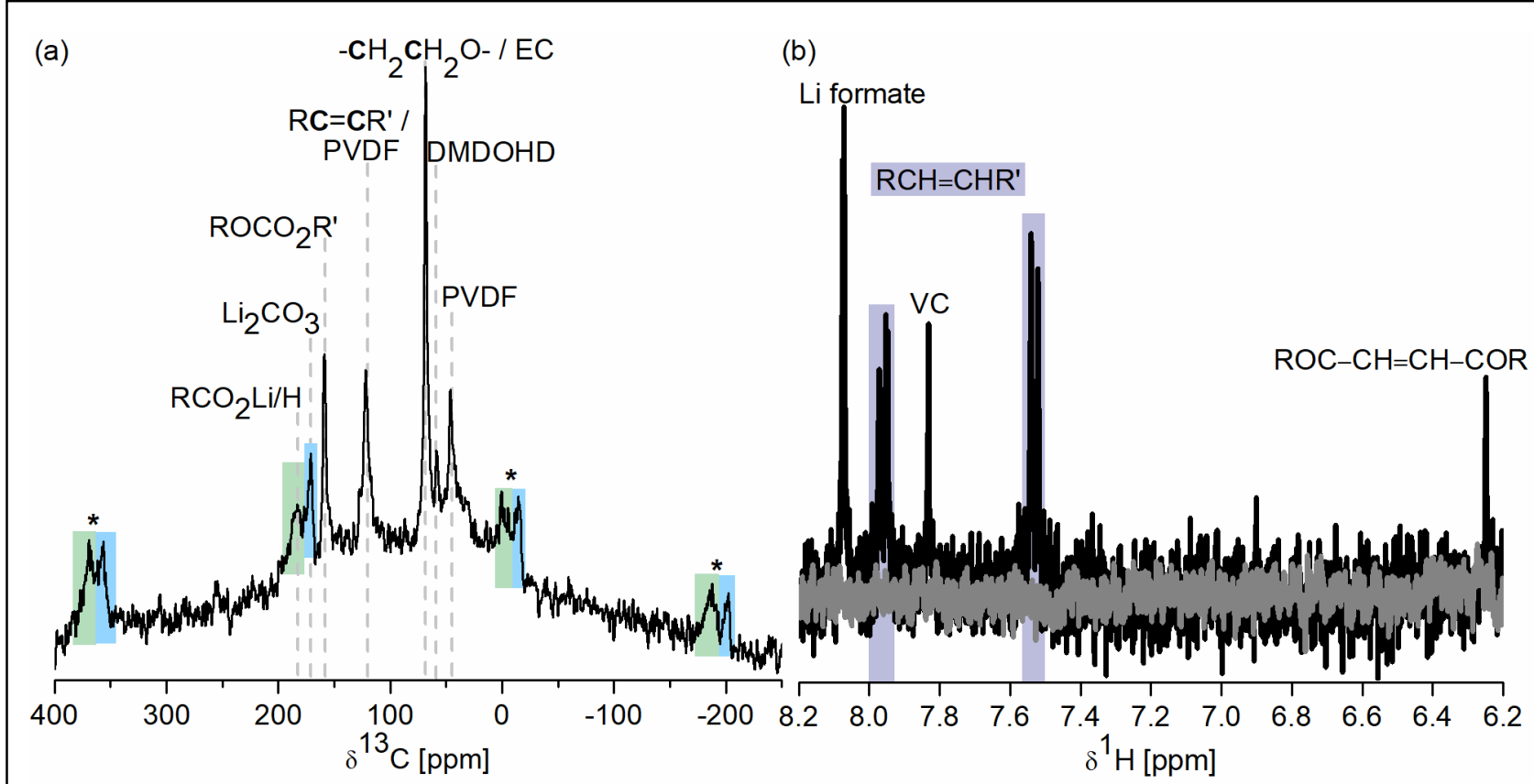

Figure 2. (a) Direct polarization ${ }^{13} \mathrm{C}$ MAS SSNMR of a NMC811 cathode film that underwent 50 galvanostatic cycles at $\mathrm{C} / 10$ and was dissembled at $4.6 \mathrm{~V}$ vs $\mathrm{Li} / \mathrm{Li}^{+}$. MAS frequency $=28 \mathrm{kHz}$. Asterisks denote spinning sidebands. (b) In situ solution ${ }^{1} \mathrm{H}$ NMR from a NMC811/Li battery in an NMR tube cell after 10 galvanostatic cycles at $\mathrm{C} / 10$ between $3.0-4.6 \mathrm{~V}$.

expected from our EPR measurements, the weak paramagnetism associated with NMC811 at charge enables high resolution ${ }^{13} \mathrm{C}$ SSNMR, where a variety of electrolyte decomposition products are observed. The resonance at $\sim 171 \mathrm{ppm}$ is assigned to $\mathrm{Li}_{2} \mathrm{CO}_{3}$ and the broad resonance centered at $\sim 185$ ppm is characteristic of structures containing carboxy groups $\left(\mathrm{RCO}_{2} \mathrm{Li} / \mathrm{H}\right) .{ }^{40,44}$ Carboxy-containing structures can be generated from electrolyte oxidation reactions at the cathode that also produce $\mathrm{CO}_{2}$ and water. ${ }^{19}$ In situ ${ }^{1} \mathrm{H}$ solution NMR shows the presence of Li formate at $8.08 \mathrm{ppm}$, which is likely generated from reduction of $\mathrm{CO}_{2}$ gas at the anode ${ }^{19}$ side of the battery (Figure $2 \mathbf{b}$ ). The large ${ }^{13} \mathrm{C}$ resonance at $\sim 69 \mathrm{ppm}$ is assigned to poly(ethylene oxide) (PEO)-type moieties that are present in the CEI layer and/or residual ethylene carbonate (EC). ${ }^{44}$ The ${ }^{13} \mathrm{C}$ resonance at $\sim 159 \mathrm{ppm}$ is assigned to the carbonyl carbon $\left(\mathrm{ROCO}_{2} \mathrm{R}^{\prime}\right)$ in alkyl carbonates and/or residual EC/DMC. We also observe a small ${ }^{13} \mathrm{C}$ resonance at $\sim 58 \mathrm{ppm}$ that corresponds to DMDOHD (dimethyl 2,5-dioxahexanedioate), a soluble decomposition product of DMC solvent. ${ }^{57,74,75}$ The assignment of DMDOHD in ${ }^{13} \mathrm{C}$ SSNMR is supported by the observation of DMDOHD in ex situ ${ }^{1} \mathrm{H}$ and ${ }^{13} \mathrm{C}$ solution NMR (Figure S7). The small resonance at $\sim 32 \mathrm{ppm}$ is assigned to the aliphatic $\left(\mathrm{RCH}_{2} \mathrm{CH}_{2} \mathrm{R}^{\prime}\right)$ environment in short-chain decomposition products such as LBDC (lithium butylene dicarbonate) and/or Li succinate. ${ }^{43,44}$ PVDF binder in the composite produces ${ }^{13} \mathrm{C}$ resonances at $45 \mathrm{ppm}$ and $122 \mathrm{ppm}$, corresponding to the $\underline{\mathbf{C H}}_{2} \mathrm{CF}_{2}$ - and $-\mathrm{CH}_{2} \underline{\mathbf{C F}}_{2}$ - groups in PVDF, respectively. However, careful inspection of the relative 
357

358

359

360

361

362

363

364

365

366

367

368

369

370

371

372

373

374

375

376

377

378

379

380

381

382

383

384

385

386

387

388

389

390

391

392

393

394

395

396

397

398

399 ratios of - $\underline{\mathbf{C H}}_{2} \mathrm{CF}_{2}-:-\mathrm{CH}_{2} \underline{\mathbf{C F}}_{2}$ - in pristine PVDF (Figure S8) compared to our cathode film indicates that the resonance at $122 \mathrm{ppm}$ is larger than expected. Based on this increased ${ }^{13} \mathrm{C}$ signal intensity at $122 \mathrm{ppm}$, we believe that this resonance does not solely arise from PVDF, and is likely due to the presence of unsaturated/vinyl compounds $\left(\mathrm{RC}=\mathrm{CR}\right.$ ') that also appear at this chemical shift ${ }^{42,76}$ and are observed during in situ ${ }^{1} \mathrm{H}$ solution NMR measurements (Figure 2b). The in situ ${ }^{1} \mathrm{H}$ solution NMR shows the presence of vinylene carbonate $\left({ }^{1} \mathrm{H} \text { shift at } 7.83 \mathrm{ppm}(\mathrm{s})\right)^{19,41}$ and Li formate $\left({ }^{1} \mathrm{H}\right.$ shift at 8.08 $\mathrm{ppm}(\mathrm{s})) .{ }^{19}$ The singlet at $6.25 \mathrm{ppm}$ is assigned to a symmetric $\mathrm{ROC}-\mathrm{HC}=\mathrm{CH}-\mathrm{COR}$ group ${ }^{77,78}$ and we also observe two unique asymmetric $\mathrm{RHC}=\mathrm{CHR}$ ' groups ${ }^{41}$ (both ${ }^{1} \mathrm{H}$ shifts appear as doublets with one shift centered at $7.53 \mathrm{ppm}$ and the other at $7.96 \mathrm{ppm}$ with $J_{\mathrm{H}-\mathrm{H}}=8.15 \mathrm{~Hz}$; we suspect that the difference in chemical shift arises from different $\mathrm{R}$ substituents). These vinyl species are not detected with ex situ solution NMR, suggesting that they are highly reactive. The formation of unsaturated compounds in the electrolyte is thus consistent with the detection of a $\mathrm{C}=\mathrm{C}$ resonance at approximately $122 \mathrm{ppm}$ in ${ }^{13}$ C SSNMR (Figure 2a).

Analysis of the full spectral breadth of Figure 2a shows that only certain ${ }^{13} \mathrm{C}$ resonances from the CEI on NMC811 composites exhibit spinning sidebands that span a wide spectral range (e.g., $\mathrm{Li}_{2} \mathrm{CO}_{3}$ (shaded blue) and carboxy-containing structures (shaded green) in Figure 2). Since paramagnetic coupling to NMR-observe nuclei is distance-dependent ( $r^{-3}$ relationship), we expect that compounds closest to the paramagnetic NMC particles will exhibit more line broadening (and thus a broad sideband pattern) than those deposited further away. ${ }^{51,52,54,79}$ However, the exact location of these compounds in the composite is not immediately apparent because EPR (Figure 1) indicates that both NMC811 and conductive carbon contain unpaired electrons that could induce these sideband patterns. To determine if NMC811, conductive carbon, or both components contribute to the observed SSNMR sidebands in Figure 2a, we performed a series of control experiments where bulk $\mathrm{Li}_{2} \mathrm{CO}_{3}$ was attached (via mechanical milling) to NMC811 or conductive carbon (at a 1:2 ratio of $\mathrm{Li}_{2} \mathrm{CO}_{3}: \mathrm{NMC} 811$ or conductive carbon). The ${ }^{7} \mathrm{Li}$ SSNMR spectrum of pristine $\mathrm{Li}_{2} \mathrm{CO}_{3}$ shows a relatively narrow sideband pattern, with a fwhm of $1030 \mathrm{~Hz}$ (Figure S9). After ball-milling with conductive carbon, the fwhm of the ${ }^{7} \mathrm{Li}$ SSNMR resonance for $\mathrm{Li}_{2} \mathrm{CO}_{3}$ increases slightly to $1175 \mathrm{~Hz}$, likely due to a minor increase in paramagnetic anisotropy from interaction with delocalized electrons on the conductive carbon. The largest change in line broadening is observed after ball milling $\mathrm{Li}_{2} \mathrm{CO}_{3}$ with NMC811, where we see a ${ }^{7} \mathrm{Li} \mathrm{fwhm}$ of approximately $1580 \mathrm{~Hz}$. Likewise, the corresponding ${ }^{13} \mathrm{C}$ SSNMR spectrum of $\mathrm{Li}_{2} \mathrm{CO}_{3}: \mathrm{NMC} 811$ (Figure S10) shows a sideband pattern that spans from +300 to $-200 \mathrm{ppm}$, similar to that observed in ${ }^{13} \mathrm{C}$ SSNMR of the CEI on NMC811 (Figure 2a). No sidebands are observed for $\mathrm{Li}_{2} \mathrm{CO}_{3}$ :carbon and we had to use a longer recycle delay (10 s vs $\left.0.8 \mathrm{~s}\right)$ to detect ${ }^{13} \mathrm{C}$ SSNMR of $\mathrm{Li}_{2} \mathrm{CO}_{3}$ :carbon, which is consistent with slower $T_{1}$ relaxation times for $\mathrm{Li}_{2} \mathrm{CO}_{3}$ attached to carbon rather than NMC811 (i.e., less paramagnetic relaxation enhancement). ${ }^{54}$ The similarities between the spinning sideband patterns and the nuclear relaxation rates for the $\mathrm{Li}_{2} \mathrm{CO}_{3}: \mathrm{NMC} 811$ control sample and the CEI on NMC composite films strongly suggest that the spinning sideband patterns observed for $\mathrm{Li}_{2} \mathrm{CO}_{3}$ and carboxy moieties in Figure 2a arise from attachment to NMC811 particles, ${ }^{52}$ and not conductive carbon.

Conversely, the lack of a spinning sideband pattern for certain CEI components in ${ }^{13} \mathrm{C}$ SSNMR (vinyl compounds, $\mathrm{PEO} /$ residual solvent, DMDOHD) indicates that these compounds are further from the NMC811 surface. Yet, these species could be located (1) in the outer CEI layer that lies directly on NMC811 particles or (2) on the surface of the carbon additives in the composite where they do not 

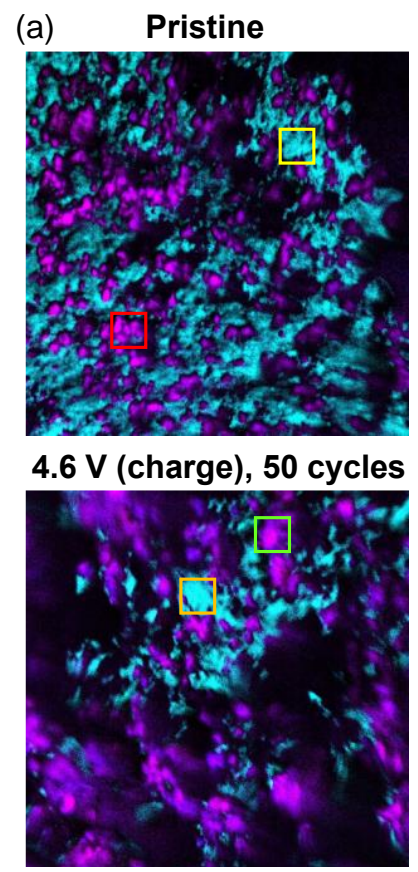

(b) LiF distribution on cycled NMC811
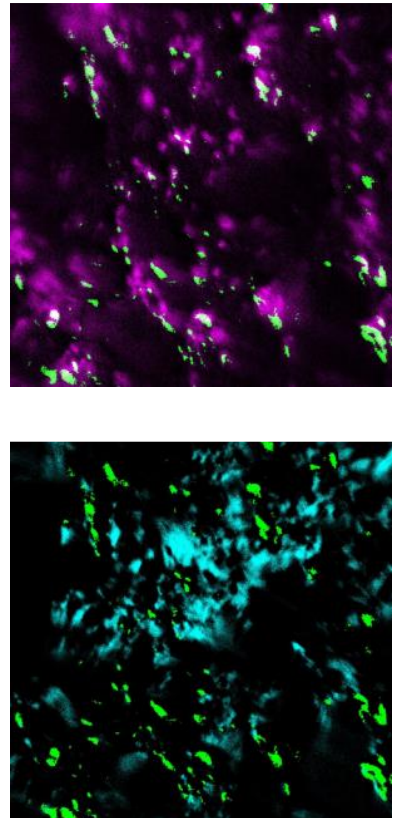

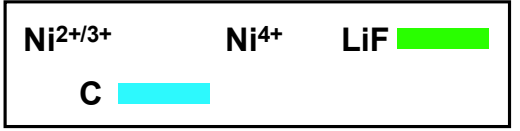

(c) F K-edge on cycled NMC

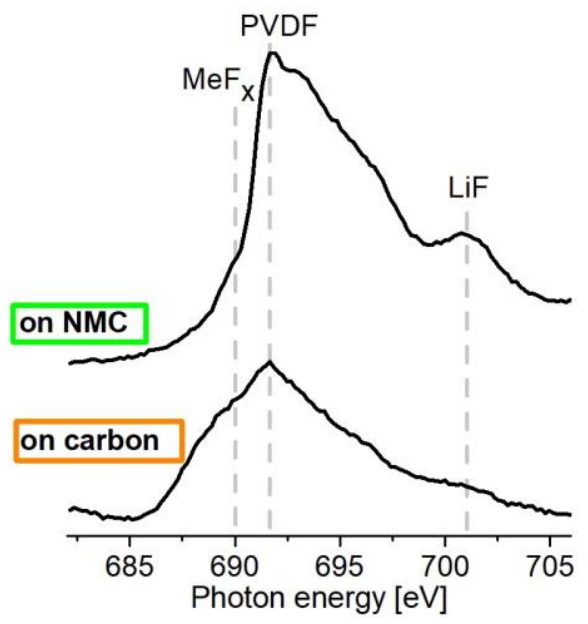

Figure 3. (a) Elemental XPEEM images (area $=30 \times 30 \mu \mathrm{m}^{2}$ ) of pristine NMC811 (top) and NMC811 composites after 50 galvanostatic cycles (bottom) at $\mathrm{C} / 5$ and disassembled at $4.6 \mathrm{~V}$ vs $\mathrm{Li} / \mathrm{Li}^{+}$. Ni elemental maps (dark blue/magenta color) show the distribution of NMC particles in the composite. Cyan indicates regions of conductive carbon. (b) Elemental XPEEM images from the cycled sample from (a) showing the LiF elemental map (green) extracted from the XPEEM image at $702 \mathrm{eV}$. The top image shows the $\mathrm{Ni}^{2+}$ map (magenta) overlaid with the $\mathrm{LiF}$ map (green). The bottom image shows the regions corresponding to conductive carbon (cyan) and LiF (green). The elemental maps in (b) indicate that LiF is selectively deposited on the surface of NMC811 particles. (c) F K-edge local XAS spectra extracted from the cycled composite shown in (a) with regions corresponding to NMC811 particles and conductive carbon highlighted with green and orange boxes. Local C K-edge spectra for these regions and the red/yellow boxes in the pristine sample in (a) are shown in Figure S13.

400

401

402

403

404

405

406

407

408

409

410

411

412

413

414

interact with unpaired electrons from the paramagnetic NMC particles. To understand the lateral distribution of the CEI on NMC811 films, we used XPEEM elemental imaging (Figure 3). In XPEEM, XAS spectra are recorded as a function of position on the composite surface, allowing us to map the location of active particles (through $\mathrm{Ni}$ L-edge spectroscopy), conductive carbon (C K-edge spectroscopy), PVDF binder (F K-edge spectroscopy), and CEI components (from unique binding energies in $\mathrm{C}$ and $\mathrm{F}$ K-edge spectroscopies). Figure $\mathbf{3}$ shows elemental XPEEM images depicting the lateral arrangement of NMC811 particles (magenta/dark blue, depending on Ni oxidation state) with respect to conductive carbon (cyan). Ni L-edge XAS spectra (Figure S11) were used to locate active particles in the cathode composite and generate the XPEEM images in Figure 3. True intensities were used in the color maps for the $\mathrm{Ni}^{2+/ 3+}$ (magenta) and conductive carbon (cyan) (Figure 3). For XPEEM maps of the $\mathrm{Ni}$ L-edge, the $\mathrm{Ni}^{4+}$ maps' $(850.0 \mathrm{eV}$, dark blue) image intensities were renormalized to emphasize the changing ratio between the two $\mathrm{L}_{3}$ edge peaks upon charge. The real intensity values of the $\mathrm{Ni}^{4+}$ maps were multiplied by the ratio obtained from dividing the maximum intensity of the Ni Ledge component at $855.8 \mathrm{eV}\left(\mathrm{Ni}^{3+/ 4+}\right)$ by the component at $853.4 \mathrm{eV}\left(\mathrm{Ni}^{2+}\right)$ in Figure $\mathbf{S 1 1}$. The LiF map in Figure 3b was produced by subtracting the LiF slice at $702.0 \mathrm{eV}$ from the slice at $689.0 \mathrm{eV}$ 
415 (corresponding to the left shoulder of the PVDF peak) to remove the contribution from PVDF to the 416 LiF slice while avoiding subtraction of the low intensity LiF peak that may overlap with PVDF sites. 417 (Figure 3c shows that the broad PVDF peak has a shoulder that slightly overlaps with the LiF peak). 418 The resulting LiF image was then thresholded to only show high intensity regions, ultimately producing 419 a single intensity map that indicates the spatial distribution of high LiF regions.

Analysis of the Ni L-edge XAS spectra supports the presence of a thin $\mathrm{Ni}^{2+}$ reconstruction layer on the cycled sample based on the fact that the peak intensity of the $\mathrm{Ni}^{2+/ 3+}$ transition $(853.5 \mathrm{eV})$ is higher than that of the $\mathrm{Ni}^{4+}$ transition $(855.9 \mathrm{eV}$ ) 31 even on the delithiated sample (Figure 3a, bottom and Figure S11, note that XPEEM is a surface sensitive technique and does not represent bulk oxidation states). In the pristine NMC811 film (Figure 3a, top), we observe a heterogeneous distribution of carbon about the NMC particles. Dark regions at the top right of the pristine film correspond to the location of $\mathrm{Au}$ particles used for $\mathrm{C} \mathrm{K}$-edge normalization (see Methods section). After 50 cycles (Figure 3a, bottom), additional dark regions are observed due to the surface roughening that occurs during electrochemical cycling.

Figure 3b shows the F K-edge elemental maps that depict the spatial distribution of LiF with respect to NMC811 and the carbon additives after 50 galvanostatic cycles and disassembled at $4.6 \mathrm{~V}$; representative local XAS spectra are shown in Figure 3c. Both F K-edge spectra from NMC particles and carbon additives show a broad peak at $693 \mathrm{eV}$ that corresponds to the PVDF binder distributed throughout the composite, which is supported by the location of PVDF seen in XPEEM maps from $F$ K-edge spectra (Figures S12-13) and agrees with prior XPEEM reports on Ni-rich composite cathodes. ${ }^{55,80}$ The breadth of the PVDF absorption peak makes it difficult to discern the presence of metal fluoride $\left(\mathrm{MeF}_{\mathrm{x}}\right)$-type compounds at $690 \mathrm{eV}^{55,80}$ that are proposed to deposit in the $\mathrm{CEI},{ }^{72}$ although a slight shoulder in this region is more apparent local to the NMC particles (Figure 3c). In contrast, $\mathrm{LiF}$ in the CEI shows a distinct peak at $702 \mathrm{eV}^{80}$ and deposits preferentially on NMC811 particles rather than the carbon additives (Figure $\mathbf{3 b}$ and $\mathbf{3 c}$ ).

In principle, $\mathrm{LiF}$ can be generated from reaction of surface $\mathrm{Li}_{2} \mathrm{CO}_{3}$ on $\mathrm{NMC} 811$ and $\mathrm{HF}$ in the electrolyte as follows:

443 In situ ${ }^{19} \mathrm{~F}$ solution NMR detects HF at $-190 \mathrm{ppm}^{19,81,82}$ upon electrochemical cycling of Li/NMC811 444 half cells (Figure 4). The resonance at $-85.2 \mathrm{ppm}\left(\mathrm{d}, J_{\mathrm{P}-\mathrm{F}}=930 \mathrm{~Hz}\right)$ is assigned to $\mathrm{PF}_{2} \mathrm{O}_{2}{ }^{-}$, a reaction 445 product from hydrolysis of $\mathrm{PF}_{6}{ }^{-}$. Small quantities of $\mathrm{PF}_{2} \mathrm{O}_{2}{ }^{-}$are also observed in the pristine electrolyte, 


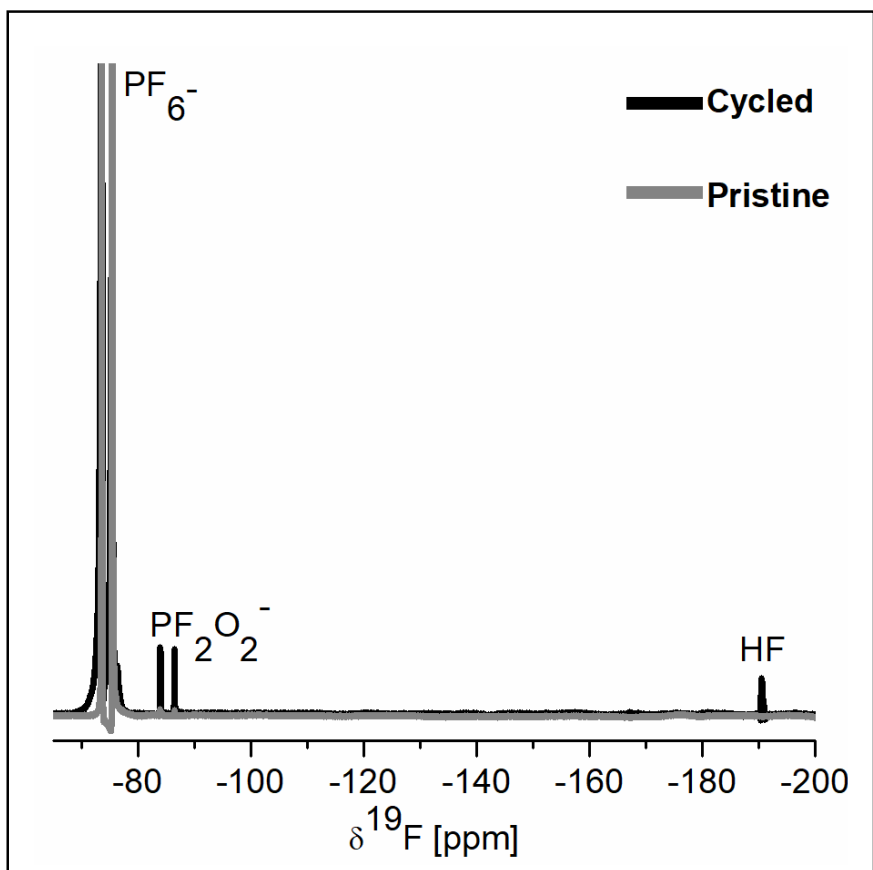

Figure 4. In situ solution ${ }^{19} \mathrm{~F}$ NMR from a NMC811/Li battery in a NMR tube cell after 10 galvanostatic cycles at $\mathrm{C} / 10$ from $3.0-4.6 \mathrm{~V}$. indicating that this compound is produced from trace water in the as-purchased, battery grade electrolyte. ${ }^{18,19,83}$ On the other hand, the presence of HF could only be observed with in situ metrology, which is consistent with the reactive nature of $\mathrm{HF}$. No $\mathrm{HF}$ is detected in the pristine electrolyte, indicating that $\mathrm{HF}$ is primarily generated from hydrolysis of $\mathrm{LiPF}_{6}$ upon electrolyte oxidation rather than from trace water in the battery grade electrolyte. Oxidation of $\mathrm{EC}$ and DMC solvents is proposed to produce carboxylic acids, $\mathrm{CO}_{2}$, and $\mathrm{H}_{2} \mathrm{O} .{ }^{9,19}$ This $\mathrm{H}_{2} \mathrm{O}$ then serves as the source of $\mathrm{LiPF}_{6}$ hydrolysis that forms $\mathrm{HF}$. Once $\mathrm{HF}$ is present in the electrolyte, it reacts with $\mathrm{Li}_{2} \mathrm{CO}_{3}$ on the surface of NMC811 to form LiF that remains directly attached to the active material during battery operation.

Local C K-edge XAS (Figure S14) spectra from the XPEEM images on the cycled NMC sample indicate that organic carbonate structures are deposited on both NMC as well as the carbon additives. The $\mathrm{C} \mathrm{K}$-edge spectra are dominated by peaks from conductive carbon at $285.4 \mathrm{eV}$ and $291.9 \mathrm{eV}$ that correspond to $\pi$ and $\sigma$
transitions, respectively. ${ }^{37}$ Regions corresponding to $\pi$ and $\sigma$ transitions are also observed on the NMC particles, suggesting that conductive carbon is also present in these regions and/or these XAS features arise from other $\mathrm{sp}^{2}$ hybridized carbon molecules in the CEI layer (e.g., vinyl species). Local C K-edge spectra extracted from pristine NMC811 particles also exhibit a shoulder at $290.4 \mathrm{eV}$ that is assigned to $\mathrm{Li}_{2} \mathrm{CO}_{3} .{ }^{55,56}$ This assignment is consistent with the spinning sideband pattern observed for $\mathrm{Li}_{2} \mathrm{CO}_{3}$ in ${ }^{13} \mathrm{C} \mathrm{SSNMR}$ as well as the location of $\mathrm{LiF}$ on NMC811 (that we believe is generated from $\mathrm{Li}_{2} \mathrm{CO}_{3}$ ). Upon electrochemical cycling, we observe a more clearly defined peak at $290.8 \mathrm{eV}$ on both NMC and the conductive carbon that may correspond to the EC/DMC-derived species observed in SSNMR (e.g., alkyl carbonates, DMDOHD) ${ }^{56,84}$ Likewise, the broad absorption at $287.5 \mathrm{eV}$ is assigned aliphatic carbon environments from these short-chain alkyl carbonates as well as the PVDF binder. ${ }^{56,85,86}$ Taken together, the $\mathrm{C} \mathrm{K}$-edge results indicate that alkyl carbonates deposit on both the carbon and the active material, and are consistent with the soluble nature of these species in the outer CEI, ${ }^{46,87}$ such as DMDOHD, which is also detected in solution NMR experiments (Figure S7). We suspect that these organic molecules are distributed randomly across the cathode film as a result of their solubility, indicating that they desorb from the interphase and fail to protect the cathode during electrochemical cycling. ${ }^{46,87}$ 


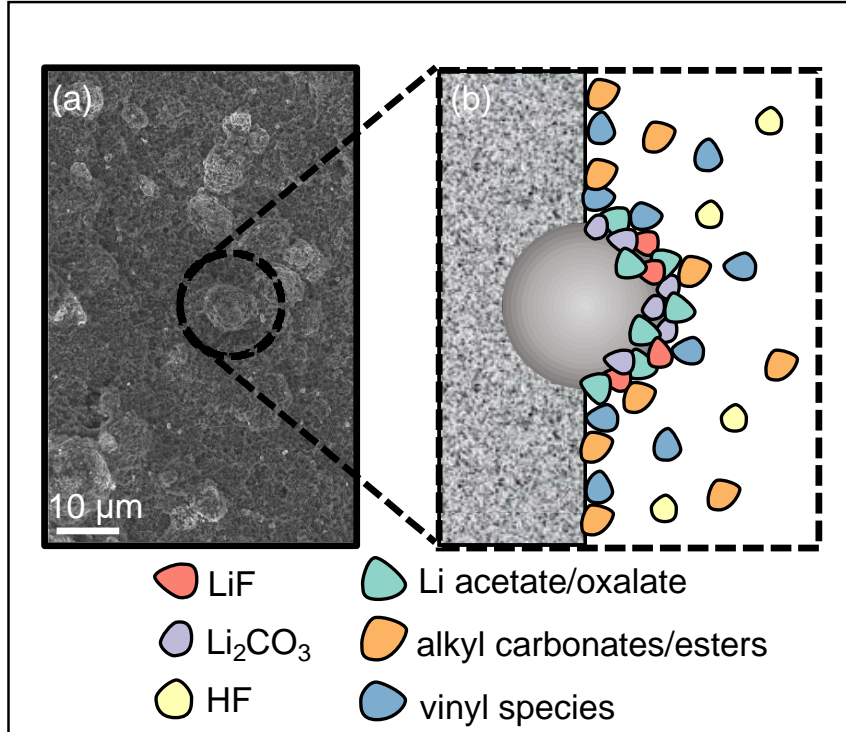

Figure 5. (a) Scanning electron microscopy (SEM) image of the surface of a NMC811 composite cathode film, with an NMC particle circled. (b) Schematic diagram depicting how the CEI is deposited on a composite cathode film during electrochemical cycling. (b) shows the cross section of the electrolyte-facing cathode film. An NMC811 particle is shown as a light grey sphere, carbon additives are shown in speckled grey, and the electrolyte is shown in white.

Figure 5 summarizes the chemical insight gained from SSNMR, in situ solution NMR, and XPEEM on the radial and lateral arrangement of the CEI on NMC811 composite films. Coupling to residual paramagnetic centers in NMC811 (e.g., $\mathrm{Mn}^{4+}$ and surface $\mathrm{NiO})$ after electrochemical cycling leads to spinning sideband patterns for $\mathrm{Li}_{2} \mathrm{CO}_{3}$ and carboxy-containing compounds in the CEI that are attached to the surface of active particles. Based on both XPEEM and SSNMR, we believe that $\mathrm{Li}_{2} \mathrm{CO}_{3}$ is present as a native CEI component on pristine NMC811 (leftover from synthesis or from exposure to moisture ${ }^{88}$ ) that can be altered during electrolyte oxidation. Electrolyte solvent oxidation at the cathode that produces particle-bound carboxy-containing CEI compounds, water, and $\mathrm{CO}_{2}$. The water produced during these reactions hydrolyzes $\mathrm{LiPF}_{6}$ salt in the electrolyte, forming $\mathrm{HF}$ that can attack $\mathrm{Li}_{2} \mathrm{CO}_{3}$ and leads to the NMC811-bound $\mathrm{LiF}$ detected in XPEEM. Note that some $\mathrm{Li}_{2} \mathrm{CO}_{3}$ is likely still bound to the NMC811 surface after electrochemical cycling, as indicated by ${ }^{13} \mathrm{C}$ SSNMR measurements, but cannot be resolved due to spectral overlap with other CEI components in $\mathrm{C} \mathrm{K}$-edge spectra. The presence of high quantities of organic carbonates in the

515

516

517

518

519

520

521

522

523

524

525

\section{6}

527

528

529

530

531

514 CEI on Ni-rich cathodes is consistent with findings from Manthiram and coworkers who used a combination of X-ray photoelectron spectroscopy (XPS) and time-of-flight secondary ion mass spectrometry (TOF-SIMS) to show that oxygen evolution at high voltages produces numerous carbonate-containing structures ${ }^{89}$ Electrolyte oxidation at the cathode also produces highly soluble CEI components such as unsaturated carbons (decomposition products that possibly arise from solvent dehydrogenation ${ }^{4}$ ) and short-chain alkyl carbonates (e.g., DMDOHD) that fail to passivate the active material. Prior work from Shao-Horn and coworkers suggests that the formation of these vinyl species is correlated with higher $\mathrm{Ni}$ content active materials and leads to performance decline during usage., ${ }^{4,33}$ Strategies that mitigate interaction between the Ni-rich surface and the liquid electrolyte (e.g., coatings) are expected to prevent the formation of these soluble decomposition products and improve LIB performance.

\section{Conclusions}

We demonstrate that SSNMR can be used to analyze the radial arrangement of the CEI from active material particles in Ni-rich composite cathode films. EPR measurements indicate that high resolution SSNMR is enabled by dilution of the paramagnetic matrix upon oxidation of $\mathrm{Ni}^{2+13+}$ to $\mathrm{Ni}^{4+}$ and can likely be extended to other Ni-rich transition metal oxides that are of technological interest (e.g., $\mathrm{LiNi}_{1-\mathrm{x}-\mathrm{y}} \mathrm{Co}_{\mathrm{x}} \mathrm{Al}_{\mathrm{y}} \mathrm{O}_{2}$ ). XPEEM imaging complements SSNMR measurements by confirming the 
532

533

534

535

536

537

538

539

540

541

542

543

lateral distribution of electrolyte decomposition products on the composite surface, where reaction of residual $\mathrm{Li}_{2} \mathrm{CO}_{3}$ generates an active material-bound CEI layer consisting of insoluble LiF. Soluble organic compounds in the CEI can detach from the particle surface and randomly deposit on the outer CEI of the active material as well as the carbon additives. The detection of many soluble electrolyte oxidation products (e.g., vinyl groups and HF) was accomplished via in situ NMR spectroscopy and provided key evidence of reactions between the active material, $\mathrm{CO}_{2}$, and water that lead to the resulting CEI compositional arrangement. The molecular-level information provided by SSNMR and XPEEM can be leveraged to provide mechanistic insight into how specific cycling protocols (e.g., altering upper cutoff voltage) and coating strategies may alleviate particular modes of battery degradation. More broadly, we expect that these techniques can be extended to monitor chemical reactivity at complex electrochemical interfaces used in a wide range of applications for energy storage, conversion, and harvesting.

\section{Supporting Information}

Electrochemical cycling data, EPR spectra, solution NMR spectra, SSNMR spectra, ${ }^{1} \mathrm{H} T_{1}$ relaxometry results, XPEEM results and associated XAS spectra can be found in the supplementary information free of charge. The NMR spectral datasets presented in this study can be accessed freely on the Open Science Framework (OSF) online repository at DOI: 10.17605/OSF.IO/VXUZC

\section{Acknowledgments}

This work was supported by National Science Foundation CAREER Award (CBET-2045262). This research used resources of the Center for Functional Nanomaterials and the National Synchrotron Light Source II, which are U.S. Department of Energy (DOE) Office of Science facilities at Brookhaven National Laboratory, under Contract No. DE-SC0012704. L.E.M. acknowledges support from Columbia University's Provost Grants Program for Junior Faculty who Contribute to the Diversity Goals of the University. J.C.H. is supported by the National Science Foundation Graduate Research Fellowship Program (NSF GRFP \# 2021278071). R.M. is supported by the U.S. Department of Defense through the National Defense Science \& Engineering Graduate (NDSEG) Fellowship Program. N.M. is supported by the Science Pathways Scholars Program of Barnard College of Columbia University.

\section{References}

(1) Kasnatscheew, J.; Röser, S.; Börner, M.; Winter, M. Do Increased Ni Contents in $\mathrm{LiNi}_{X} \mathrm{Mn}_{Y} \mathrm{Coz}_{2}$ (NMC) Electrodes Decrease Structural and Thermal Stability of Li Ion Batteries? A Thorough Look by Consideration of the $\mathrm{Li}^{+}$Extraction Ratio. ACS Appl. Energy Mater. 2019, 2 (11), 7733-7737. https://doi.org/10.1021/acsaem.9b01440.

(2) Li, T.; Yuan, X.-Z.; Zhang, L.; Song, D.; Shi, K.; Bock, C. Degradation Mechanisms and Mitigation Strategies of Nickel-Rich NMC-Based Lithium-Ion Batteries. Electrochem. Energy Rev. 2020, 3 (1), 43-80. https://doi.org/10.1007/s41918-019-00053-3.

(3) Gourley, S. W. D.; Or, T.; Chen, Z. Breaking Free from Cobalt Reliance in Lithium-Ion Batteries. iScience. Elsevier Inc. September 25, 2020, p 101505. https://doi.org/10.1016/j.isci.2020.101505. 
572

573

574

575

576

577

578

579

580

581

582

583

584

585

586

587

588

589

590

591

592

593

594

595

596

597

598

599

600

601

602

603

604

605

606

607

608

609

610

611

(4) Zhang, Y.; Katayama, Y.; Tatara, R.; Giordano, L.; Yu, Y.; Fraggedakis, D.; Sun, J. G.; Maglia, F.; Jung, R.; Bazant, M. Z.; Shao-Horn, Y. Revealing Electrolyte Oxidation: Via Carbonate Dehydrogenation on Ni-Based Oxides in Li-Ion Batteries by in Situ Fourier Transform Infrared Spectroscopy. Energy Environ. Sci. 2020, 13 (1), 183-199. https://doi.org/10.1039/c9ee02543j.

(5) Sun, H. H.; Manthiram, A. Impact of Microcrack Generation and Surface Degradation on a Nickel-Rich Layered $\mathrm{Li}\left[\mathrm{Ni}_{0.9} \mathrm{Co}_{0.05} \mathrm{Mn}_{0.05}\right] \mathrm{O}_{2}$ Cathode for Lithium-Ion Batteries. Chem. Mater. 2017, 29 (19), 8486-8493. https://doi.org/10.1021/acs.chemmater.7b03268.

(6) Ryu, H. H.; Park, K. J.; Yoon, C. S.; Sun, Y. K. Capacity Fading of Ni-Rich Li[Ni $\mathrm{Ni}_{\mathrm{x}} \mathrm{Co}_{\mathrm{y}} \mathrm{Mn}_{1-\mathrm{x}-}$ y] $\mathrm{O}_{2}(0.6 \leq \mathrm{x} \leq 0.95)$ Cathodes for High-Energy-Density Lithium-Ion Batteries: Bulk or Surface Degradation? Chem. Mater. 2018, 30 (3), 1155-1163. https://doi.org/10.1021/acs.chemmater.7b05269.

(7) Yan, P.; Zheng, J.; Gu, M.; Xiao, J.; Zhang, J.-G.; Wang, C.-M. Intragranular Cracking as a Critical Barrier for High-Voltage Usage of Layer-Structured Cathode for Lithium-Ion Batteries. Nat. Commun. 201781 2017, 8 (1), 1-9. https://doi.org/10.1038/ncomms 14101.

(8) Xu, Z.; Rahman, M. M.; Mu, L.; Liu, Y.; Lin, F. Chemomechanical Behaviors of Layered Cathode Materials in Alkali Metal Ion Batteries. Journal of Materials Chemistry A. The Royal Society of Chemistry November 13, 2018, pp 21859-21884. https://doi.org/10.1039/c8ta06875e.

(9) Jung, R.; Metzger, M.; Maglia, F.; Stinner, C.; Gasteiger, H. A. Oxygen Release and Its Effect on the Cycling Stability of $\mathrm{LiNi}_{x} \mathrm{Mn}_{\mathrm{y}} \mathrm{Co}_{\mathrm{z}} \mathrm{O}_{2}$ (NMC) Cathode Materials for Li-Ion Batteries. $J$. Electrochem. Soc. 2017, 164 (7), A1361-A1377. https://doi.org/10.1149/2.0021707jes.

(10) Renfrew, S. E.; McCloskey, B. D. Residual Lithium Carbonate Predominantly Accounts for First Cycle $\mathrm{CO}_{2}$ and $\mathrm{CO}$ Outgassing of Li-Stoichiometric and Li-Rich Layered TransitionMetal Oxides. J. Am. Chem. Soc. 2017, 139 (49), 17853-17860. https://doi.org/10.1021/jacs.7b08461.

(11) Kong, F.; Liang, C.; Wang, L.; Zheng, Y.; Perananthan, S.; Longo, R. C.; Ferraris, J. P.; Kim, M.; Cho, K. Kinetic Stability of Bulk $\mathrm{LiNiO}_{2}$ and Surface Degradation by Oxygen Evolution in $\mathrm{LiNiO}_{2}$-Based Cathode Materials. Adv. Energy Mater. 2019, 9 (2), 1802586. https://doi.org/10.1002/aenm.201802586.

(12) Lin, F.; Markus, I. M.; Nordlund, D.; Weng, T. C.; Asta, M. D.; Xin, H. L.; Doeff, M. M. Surface Reconstruction and Chemical Evolution of Stoichiometric Layered Cathode Materials for Lithium-Ion Batteries. Nat. Commun. 2014, 5, 3529. https://doi.org/10.1038/ncomms4529.

(13) Xu, C.; Märker, K.; Lee, J.; Mahadevegowda, A.; Reeves, P. J.; Day, S. J.; Groh, M. F.; Emge, S. P.; Ducati, C.; Layla Mehdi, B.; Tang, C. C.; Grey, C. P. Bulk Fatigue Induced by Surface Reconstruction in Layered Ni-Rich Cathodes for Li-Ion Batteries. Nat. Mater. 2020, 1-9. https://doi.org/10.1038/s41563-020-0767-8.

(14) Carroll, K. J.; Qian, D.; Fell, C.; Calvin, S.; Veith, G. M.; Chi, M.; Baggetto, L.; Meng, Y. S. Probing the Electrode/Electrolyte Interface in the Lithium Excess Layered Oxide $\mathrm{Li}_{1.2} \mathrm{Ni}_{0.2} \mathrm{Mn}_{0.6} \mathrm{O}_{2}$. Phys. Chem. Chem. Phys. 2013, 15 (26), 11128-11138.

This is a provisional file, not the final typeset article 
613

614

615

616

617

618

619

620

621

622

623

624

625

626

627

628

629

630

631

632

633

634

635

636

637

638

639

640

641

642

643

644

645

646

647

648

649

650

(15) Wandt, J.; Freiberg, A.; Thomas, R.; Gorlin, Y.; Siebel, A.; Jung, R.; Gasteiger, H. A.; Tromp, M. Transition Metal Dissolution and Deposition in Li-Ion Batteries Investigated by Operando X-Ray Absorption Spectroscopy. J. Mater. Chem. A 2016, 4 (47), 18300-18305. https://doi.org/10.1039/C6TA08865A.

(16) Li, W.; Dolocan, A.; Oh, P.; Celio, H.; Park, S.; Cho, J.; Manthiram, A. Dynamic Behaviour of Interphases and Its Implication on High-Energy-Density Cathode Materials in Lithium-Ion Batteries. Nat. Commun. 2017. https://doi.org/10.1038/ncomms 14589.

(17) Su, C.-C.; He, M.; Amine, R.; Chen, Z.; Yu, Z.; Rojas, T.; Cheng, L.; Ngo, A. T.; Amine, K. Unveiling Decaying Mechanism through Quantitative Structure-Activity Relationship in Electrolytes for Lithium-Ion Batteries. Nano Energy 2021, 83, 105843. https://doi.org/10.1016/j.nanoen.2021.105843.

(18) Yu, Y.; Karayaylali, P.; Katayama, Y.; Giordano, L.; Gauthier, M.; Maglia, F.; Jung, R.; Lund, I.; Shao-Horn, Y. Coupled $\mathrm{LiPF}_{6}$ Decomposition and Carbonate Dehydrogenation Enhanced by Highly Covalent Metal Oxides in High-Energy Li-Ion Batteries. J. Phys. Chem. C 2018, 122 (48), 27368-27382. https://doi.org/10.1021/acs.jpcc.8b07848.

(19) Rinkel, B.; Hall, D. S.; Temprano, I.; Grey, C. P. Electrolyte Oxidation Pathways in LithiumIon Batteries. J. Am. Chem. Soc. 2020. https://doi.org/10.1021/jacs.0c06363.

(20) Ohzuku, T.; Ueda, A.; Nagayama, M. Electrochemistry and Structural Chemistry of $\mathrm{LiNiO}_{2}$ (R3m) for 4 Volt Secondary Lithium Cells. J. Electrochem. Soc. 1993, 140 (7), 1862. https://doi.org/10.1149/1.2220730.

(21) Yoon, C. S.; Jun, D.-W.; Myung, S.-T.; Sun, Y.-K. Structural Stability of $\mathrm{LiNiO}_{2}$ Cycled above 4.2 V. 2017, 2. https://doi.org/10.1021/acsenergylett.7b00304.

(22) Märker, K.; Reeves, P. J.; Xu, C.; Griffith, K. J.; Grey, C. P. Evolution of Structure and Lithium Dynamics in $\mathrm{LiNi}_{0.8} \mathrm{Mn}_{0.1} \mathrm{Co}_{0.1} \mathrm{O}_{2}$ (NMC811) Cathodes during Electrochemical Cycling. Chem. Mater. 2019, 31 (7), 2545-2554. https://doi.org/10.1021/acs.chemmater.9b00140.

(23) Hy, S.; Liu, H.; Zhang, M.; Qian, D.; Hwang, B. J.; Meng, Y. S. Performance and Design Considerations for Lithium Excess Layered Oxide Positive Electrode Materials for Lithium Ion Batteries. Energy and Environmental Science. 2016, pp 1931-1954. https://doi.org/10.1039/c5ee03573b.

(24) Noh, H. J.; Youn, S.; Yoon, C. S.; Sun, Y. K. Comparison of the Structural and Electrochemical Properties of Layered $\mathrm{Li}\left[\mathrm{Ni}_{\mathrm{x}} \mathrm{Co}_{\mathrm{y}} \mathrm{Mn}_{\mathrm{z}}\right] \mathrm{O}_{2}(\mathrm{x}=1 / 3,0.5,0.6,0.7,0.8$ and 0.85$)$ Cathode Material for Lithium-Ion Batteries. J. Power Sources 2013, 233, 121-130. https://doi.org/10.1016/j.jpowsour.2013.01.063.

(25) Xia, S.; Mu, L.; Xu, Z.; Wang, J.; Wei, C.; Liu, L.; Pianetta, P.; Zhao, K.; Yu, X.; Lin, F.; Liu, Y. Chemomechanical Interplay of Layered Cathode Materials Undergoing Fast Charging in Lithium Batteries. Nano Energy 2018, 53, 753-762. https://doi.org/10.1016/j.nanoen.2018.09.051. 
651

652

653

654

655

656

657

658

659

660

661

662

663

664

665

666

667

668

669

670

671

672

673

674

675

676

677

678

679

680

681

682

683

684

685

686

687

688

689

690

(26) Gauthier, M.; Carney, T. J.; Grimaud, A.; Giordano, L.; Pour, N.; Chang, H. H.; Fenning, D. P.; Lux, S. F.; Paschos, O.; Bauer, C.; Maglia, F.; Lupart, S.; Lamp, P.; Shao-Horn, Y. Electrode-Electrolyte Interface in Li-Ion Batteries: Current Understanding and New Insights. Journal of Physical Chemistry Letters. November 11, 2015, pp 4653-4672. https://doi.org/10.1021/acs.jpclett.5b01727.

(27) Strehle, B.; Kleiner, K.; Jung, R.; Chesneau, F.; Mendez, M.; Gasteiger, H. A.; Piana, M. The Role of Oxygen Release from Li- and Mn-Rich Layered Oxides during the First Cycles Investigated by On-Line Electrochemical Mass Spectrometry. J. Electrochem. Soc. 2017, 164 (2), A400-A406. https://doi.org/10.1149/2.1001702jes.

(28) Streich, D.; Erk, C.; Guéguen, A.; Müller, P.; Chesneau, F. F.; Berg, E. J. Operando Monitoring of Early Ni-Mediated Surface Reconstruction in Layered Lithiated Ni-Co-Mn Oxides. J. Phys. Chem. C 2017, 121 (25), 13481-13486. https://doi.org/10.1021/acs.jpcc.7b02303.

(29) Berkes, B. B.; Schiele, A.; Sommer, H.; Brezesinski, T.; Janek, J. On the Gassing Behavior of Lithium-Ion Batteries with NCM523 Cathodes. J. Solid State Electrochem. 2016, 20 (11), 2961-2967. https://doi.org/10.1007/s10008-016-3362-9.

(30) Schipper, F.; Erickson, E. M.; Erk, C.; Shin, J.-Y.; Chesneau, F. F.; Aurbach, D. ReviewRecent Advances and Remaining Challenges for Lithium Ion Battery Cathodes. $J$. Electrochem. Soc. 2017, 164 (1), A6220-A6228. https://doi.org/10.1149/2.0351701jes.

(31) Yu, Y.; Karayaylali, P.; Giordano, L.; Corchado-Garciá, J.; Hwang, J.; Sokaras, D.; Maglia, F.; Jung, R.; Gittleson, F. S.; Shao-Horn, Y. Probing Depth-Dependent Transition-Metal Redox of Lithium Nickel, Manganese, and Cobalt Oxides in Li-Ion Batteries. ACS Appl. Mater. Interfaces 2020, 12 (50), 55865-55875. https://doi.org/10.1021/acsami.0c16285.

(32) Manthiram, A. An Outlook on Lithium Ion Battery Technology. ACS Cent. Sci. 2017, 3 (10), 1063-1069. https://doi.org/10.1021/acscentsci.7b00288.

(33) Giordano, L.; Karayaylali, P.; Yu, Y.; Katayama, Y.; Maglia, F.; Lux, S.; Shao-Horn, Y. Chemical Reactivity Descriptor for the Oxide-Electrolyte Interface in Li-Ion Batteries. J. Phys. Chem. Lett. 2017, 8 (16), 3881-3887. https://doi.org/10.1021/acs.jpclett.7b01655.

(34) Edström, K.; Gustafsson, T.; Thomas, J. O. The Cathode-Electrolyte Interface in the Li-Ion Battery. In Electrochimica Acta; Pergamon, 2004; Vol. 50, pp 397-403. https://doi.org/10.1016/j.electacta.2004.03.049.

(35) Demeaux, J.; Caillon-Caravanier, M.; Galiano, H.; Lemordant, D.; Claude-Montigny, B. $\mathrm{LiNi}_{0.4} \mathrm{Mn}_{1.6} \mathrm{O}_{4} /$ Electrolyte and Carbon Black/Electrolyte High Voltage Interfaces: To Evidence the Chemical and Electronic Contributions of the Solvent on the Cathode-Electrolyte Interface Formation. J. Electrochem. Soc. 2012, 159 (11), A1880-A1890. https://doi.org/10.1149/2.052211jes.

(36) Metzger, M.; Marino, C.; Sicklinger, J.; Haering, D.; Gasteiger, H. A. Anodic Oxidation of Conductive Carbon and Ethylene Carbonate in High-Voltage Li-Ion Batteries Quantified by On-Line Electrochemical Mass Spectrometry. J. Electrochem. Soc. 2015, 162 (7), A1123A1134. https://doi.org/10.1149/2.0951506jes.

This is a provisional file, not the final typeset article 
691

692

693

694

695

696

697

698

699

700

701

702

703

704

705

706

707

708

709

710

711

712

713

714

715

716

717

718

719

720

721

722

723

724

725

726

727

728

729

730

(37) Mirolo, M.; Leanza, D.; Höltschi, L.; Jordy, C.; Pelé, V.; Novák, P.; El Kazzi, M.; Vaz, C. A. F. Post Mortem and Operando XPEEM: A Surface-Sensitive Tool for Studying Single Particles in Li-Ion Battery Composite Electrodes. Anal. Chem. 2020, 92 (4), 3023-3031. https://doi.org/10.1021/acs.analchem.9b04124.

(38) Li, J.; Manthiram, A. A Comprehensive Analysis of the Interphasial and Structural Evolution over Long-Term Cycling of Ultrahigh-Nickel Cathodes in Lithium-Ion Batteries. Adv. Energy Mater. 2019, 9 (45). https://doi.org/10.1002/aenm.201902731.

(39) Leanza, D.; Vaz, C. A. F.; Novák, P.; El Kazzi, M. Instability of PVDF Binder in the $\mathrm{LiFePO}_{4}$ versus $\mathrm{Li}_{4} \mathrm{Ti}_{5} \mathrm{O}_{12}$ Li-Ion Battery Cell. Helv. Chim. Acta 2021, 104 (1). https://doi.org/10.1002/hlca.202000183.

(40) Michan, A. L.; Leskes, M.; Grey, C. P. Voltage Dependent Solid Electrolyte Interphase Formation in Silicon Electrodes: Monitoring the Formation of Organic Decomposition Products. Chem. Mater. 2016, 28 (1), 385-398. https://doi.org/10.1021/acs.chemmater.5b04408.

(41) Jin, Y.; Kneusels, N. J. H.; Magusin, P. C. M. M.; Kim, G.; Castillo-Martínez, E.; Marbella, L. E.; Kerber, R. N.; Howe, D. J.; Paul, S.; Liu, T.; Grey, C. P. Identifying the Structural Basis for the Increased Stability of the Solid Electrolyte Interphase Formed on Silicon with the Additive Fluoroethylene Carbonate. J. Am. Chem. Soc. 2017, 139 (42), 14992-15004. https://doi.org/10.1021/jacs.7b06834.

(42) Jin, Y.; Kneusels, N. J. H.; Marbella, L. E.; Castillo-Martínez, E.; Magusin, P. C. M. M.; Weatherup, R. S.; Jónsson, E.; Liu, T.; Paul, S.; Grey, C. P. Understanding Fluoroethylene Carbonate and Vinylene Carbonate Based Electrolytes for Si Anodes in Lithium Ion Batteries with NMR Spectroscopy. J. Am. Chem. Soc. 2018, 140 (31), 9854-9867. https://doi.org/10.1021/jacs.8b03408.

(43) May, R.; Zhang, Y.; Denny, S. R.; Viswanathan, V.; Marbella, L. E. Leveraging Cation Identity to Engineer Solid Electrolyte Interphases for Rechargeable Lithium Metal Anodes. Cell Reports Phys. Sci. 2020, 1 (11), 100239. https://doi.org/10.1016/j.xcrp.2020.100239.

(44) Leskes, M.; Kim, G.; Liu, T.; Michan, A. L.; Aussenac, F.; Dorffer, P.; Paul, S.; Grey, C. P. Surface-Sensitive NMR Detection of the Solid Electrolyte Interphase Layer on Reduced Graphene Oxide. J. Phys. Chem. Lett. 2017, 8 (5), 1078-1085.

https://doi.org/10.1021/acs.jpclett.6b02590.

(45) Michan, A. L.; Divitini, G.; Pell, A. J.; Leskes, M.; Ducati, C.; Grey, C. P. Solid Electrolyte Interphase Growth and Capacity Loss in Silicon Electrodes. J. Am. Chem. Soc. 2016, 138 (25), 7918-7931. https://doi.org/10.1021/jacs.6b02882.

(46) Hestenes, J. C.; Ells, A. W.; Navarro Goldaraz, M.; Sergeyev, I. V.; Itin, B.; Marbella, L. E. Reversible Deposition and Stripping of the Cathode Electrolyte Interphase on $\mathrm{Li}_{2} \mathrm{RuO}_{3}$. Front. Chem. 2020, 8, 681. https://doi.org/10.3389/fchem.2020.00681.

(47) Cuisinier, M.; Dupré, N.; Martin, J. F.; Kanno, R.; Guyomard, D. Evolution of the LiFePO Positive Electrode Interface along Cycling Monitored by MAS NMR. J. Power Sources 2013, 224, 50-58. https://doi.org/10.1016/j.jpowsour.2012.08.099. 
731

732

733

734

735

736

737

738

739

740

741

742

743

744

745

746

747

748

749

750

751

752

753

754

755

756

757

758

759

760

761

762

763

764

765

766

767

768

(48) Dupré, N.; Martin, J.-F.; Oliveri, J.; Soudan, P.; Guyomard, D.; Yamada, A.; Kanno, R. Aging of the $\mathrm{LiNi}_{12} \mathrm{Mn}_{12} \mathrm{O}_{2}$ Positive Electrode Interface in Electrolyte. J. Electrochem. Soc. 2009, 156 (5), C180. https://doi.org/10.1149/1.3098494.

(49) Haber, S.; Leskes, M. What Can We Learn from Solid State NMR on the ElectrodeElectrolyte Interface? Adv. Mater. 2018, 30 (41). https://doi.org/10.1002/ADMA.201706496.

(50) Dupre, N.; Cuisinier, M.; Guyomard, D. Electrode/Electrolyte Interface Studies in Lithium Batteries Using NMR. Electrochem. Soc. Interface 2011, 20 (3), 61-67. https://doi.org/10.1149/2.F06113if.

(51) Grey, C. P.; Dupré, N. NMR Studies of Cathode Materials for Lithium-Ion Rechargeable Batteries. Chem. Rev. 2004, 104 (10), 4493-4512. https://doi.org/10.1021/cr020734p.

(52) Dupré, N.; Martin, J. F.; Guyomard, D.; Yamada, A.; Kanno, R. Detection of Surface Layers Using ${ }^{7}$ Li MAS NMR. J. Mater. Chem. 2008, 18 (36), 4266-4273. https://doi.org/10.1039/b807778a.

(53) Cuisinier, M.; Martin, J. F.; Moreau, P.; Epicier, T.; Kanno, R.; Guyomard, D.; Dupré, N. Quantitative MAS NMR Characterization of the LiMn1/2Ni 1/2O2 Electrode/Electrolyte Interphase. Solid State Nucl. Magn. Reson. 2012, 42, 51-61. https://doi.org/10.1016/j.ssnmr.2011.09.001.

(54) Pell, A. J.; Pintacuda, G.; Grey, C. P. Paramagnetic NMR in Solution and the Solid State. Progress in Nuclear Magnetic Resonance Spectroscopy. Elsevier B.V. April 1, 2019, pp 1271. https://doi.org/10.1016/j.pnmrs.2018.05.001.

(55) Mirolo, M.; Vaz, C. A. F.; Novák, P.; El Kazzi, M. Multi-Length-Scale x-Ray Spectroscopies for Determination of Surface Reactivity at High Voltages of $\mathrm{LiNi}_{0.8} \mathrm{Co}_{0.15} \mathrm{Al}_{0.05} \mathrm{O}_{2}$ vs $\mathrm{Li}_{4} \mathrm{Ti}_{5} \mathrm{O}_{12}$. J. Chem. Phys. 2020, 152 (18), 184705. https://doi.org/10.1063/5.0006269.

(56) Zhuo, Z.; Lu, P.; Delacourt, C.; Qiao, R.; Xu, K.; Pan, F.; Harris, S. J.; Yang, W. Breathing and Oscillating Growth of Solid-Electrolyte-Interphase upon Electrochemical Cycling. Chem. Commun. 2018, 54 (7), 814-817. https://doi.org/10.1039/c7cc07082a.

(57) Wiemers-Meyer, S.; Winter, M.; Nowak, S. A Battery Cell for in Situ NMR Measurements of Liquid Electrolytes. Phys. Chem. Chem. Phys. 2017, 19 (7), 4962-4966. https://doi.org/10.1039/c6cp08653e.

(58) Zhou, L.; Leskes, M.; Liu, T.; Grey, C. P. Probing Dynamic Processes in Lithium-Ion Batteries by in Situ NMR Spectroscopy: Application to $\mathrm{Li}_{1.08} \mathrm{Mn}_{1.92} \mathrm{O}_{4}$ Electrodes. Angew. Chemie - Int. Ed. 2015, 54 (49), 14782-14786. https://doi.org/10.1002/anie.201507632.

(59) Nguyen, H.; Clément, R. J. Rechargeable Batteries from the Perspective of the Electron Spin. ACS Energy Lett. 2020, 3848-3859. https://doi.org/10.1021/acsenergylett.0c02074.

(60) Shinova, E.; Stoyanova, R.; Zhecheva, E.; Ortiz, G. F.; Lavela, P.; Tirado, J. L. Cationic Distribution and Electrochemical Performance of $\mathrm{LiCo}_{1 / 3} \mathrm{Ni}_{1 / 3} \mathrm{Mn}_{1 / 3} \mathrm{O}_{2}$ Electrodes for LithiumIon Batteries. Solid State Ionics 2008, 179 (38), 2198-2208.

https://doi.org/10.1016/j.ssi.2008.07.026.

This is a provisional file, not the final typeset article 
(61) Tang, M.; Dalzini, A.; Li, X.; Feng, X.; Chien, P. H.; Song, L.; Hu, Y. Y. Operando EPR for Simultaneous Monitoring of Anionic and Cationic Redox Processes in Li-Rich Metal Oxide Cathodes. J. Phys. Chem. Lett. 2017, 8 (17), 4009-4016. https://doi.org/10.1021/acs.jpclett.7b01425.

(62) Mukherjee, P.; Paddison, J. A. M.; Xu, C.; Ruff, Z.; Wildes, A. R.; Keen, D. A.; Smith, R. I.; Grey, C. P.; Dutton, S. E. Sample Dependence of Magnetism in the Next-Generation Cathode Material $\mathrm{LiNi}_{0.8} \mathrm{Mn}_{0.1} \mathrm{Co}_{0.1} \mathrm{O}_{2}$. Inorg. Chem. 2021, 60 (1), 263-271. https://doi.org/10.1021/acs.inorgchem.0c02899.

(63) Flores, E.; Novák, P.; Aschauer, U.; Berg, E. J. Cation Ordering and Redox Chemistry of Layered Ni-Rich $\mathrm{LixNi}_{1-2 \mathrm{Y}} \mathrm{CoyMnY}_{2}$ : An Operando Raman Spectroscopy Study. Chem. Mater. 2020, 32 (1), 186-194. https://doi.org/10.1021/acs.chemmater.9b03202.

(64) Sclar, H.; Kovacheva, D.; Zhecheva, E.; Stoyanova, R.; Lavi, R.; Kimmel, G.; Grinblat, J.; Girshevitz, O.; Amalraj, F.; Haik, O.; Zinigrad, E.; Markovsky, B.; Aurbach, D. On the Performance of $\mathrm{LiNi}_{1 / 3} \mathrm{Mn}_{1 / 3} \mathrm{Co}_{1 / 3} \mathrm{O}_{2}$ Nanoparticles as a Cathode Material for Lithium-Ion Batteries. J. Electrochem. Soc. 2009, 156 (11), A938. https://doi.org/10.1149/1.3212850.

(65) Stoyanova, R.; Barra, A. L.; Yoncheva, M.; Zhecheva, E.; Shinova, E.; Tzvetkova, P.; Simova, S. High-Frequency Electron Paramagnetic Resonance Analysis of the Oxidation State and Local Structure of $\mathrm{Ni}$ and $\mathrm{Mn}$ Ions in $\mathrm{Ni}, \mathrm{Mn}$-Codoped $\mathrm{LiCoO}_{2}$. Inorg. Chem. 2010, 49 (4), 1932-1941. https://doi.org/10.1021/ic902351u.

(66) Chernova, N. A.; Ma, M.; Xiao, J.; Whittingham, M. S.; Breger, J.; Grey, C. P. Layered $\mathrm{Li}_{\mathrm{x}} \mathrm{Ni}_{\mathrm{y}} \mathrm{Mn}_{\mathrm{y}} \mathrm{Co}_{1-2 \mathrm{y}} \mathrm{O}_{2}$ Cathodes for Lithium Ion Batteries: Understanding Local Structure via Magnetic Properties. Chem. Mater. 2007, 19 (19), 4682-4693. https://doi.org/10.1021/cm0708867.

(67) Niemöller, A.; Jakes, P.; Eurich, S.; Paulus, A.; Kungl, H.; Eichel, R. A.; Granwehr, J. Monitoring Local Redox Processes in $\mathrm{LiNi}_{0.5} \mathrm{Mn}_{1.5} \mathrm{O}_{4}$ Battery Cathode Material by in Operando EPR Spectroscopy. J. Chem. Phys. 2018, 148 (1), 14705. https://doi.org/10.1063/1.5008251.

(68) El Mofid, W.; Ivanov, S.; Konkin, A.; Bund, A. A High Performance Layered Transition Metal Oxide Cathode Material Obtained by Simultaneous Aluminum and Iron Cationic Substitution. J. Power Sources 2014, 268, 414-422. https://doi.org/10.1016/j.jpowsour.2014.06.048.

(69) Hwang, B. J.; Tsai, Y. W.; Carlier, D.; Ceder, G. A Combined Computational/Experimental Study on $\mathrm{LiNi}_{1 / 3} \mathrm{Co}_{1 / 3} \mathrm{Mn}_{1 / 3} \mathrm{O}_{2}$. Chem. Mater. 2003, 15 (19), 3676-3682. https://doi.org/10.1021/cm030299v.

(70) Mauger, A.; Gendron, F.; Julien, C. M. Magnetic Properties of $\mathrm{LiXNiYMnYCo}_{1-2 \mathrm{y}} \mathrm{O}_{2}(0.2 \leq 1$ $2 \mathrm{y} \leq 0.5,0 \leq \mathrm{x} \leq 1)$. J. Alloys Compd. 2012, 520, 42-51. https://doi.org/10.1016/j.jallcom.2011.12.055.

(71) Liu, H.; Bugnet, M.; Tessaro, M. Z.; Harris, K. J.; Dunham, M. J. R.; Jiang, M.; Goward, G. R.; Botton, G. A. Spatially Resolved Surface Valence Gradient and Structural Transformation of Lithium Transition Metal Oxides in Lithium-Ion Batteries. Phys. Chem. Chem. Phys. 2016, 
(72) Li, W.; Liu, X.; Xie, Q.; You, Y.; Chi, M.; Manthiram, A. Long-Term Cyclability of NCM811 at High Voltages in Lithium-Ion Batteries: An In-Depth Diagnostic Study. Chem. Mater. 2020, 32 (18), 7796-7804. https://doi.org/10.1021/acs.chemmater.0c02398.

(73) Tian, C.; Lin, F.; Doeff, M. M. Electrochemical Characteristics of Layered Transition Metal Oxide Cathode Materials for Lithium Ion Batteries: Surface, Bulk Behavior, and Thermal Properties. Acc. Chem. Res. 2018, 51 (1), 89-96. https://doi.org/10.1021/acs.accounts.7b00520.

(74) Wang, L.; Menakath, A.; Han, F.; Wang, Y.; Zavalij, P. Y.; Gaskell, K. J.; Borodin, O.; Iuga, D.; Brown, S. P.; Wang, C.; Xu, K.; Eichhorn, B. W. Identifying the Components of the Solid-Electrolyte Interphase in Li-Ion Batteries. Nat. Chem. 2019, 11 (9), 789-796. https://doi.org/10.1038/s41557-019-0304-z.

(75) Gachot, G.; Grugeon, S.; Armand, M.; Pilard, S.; Guenot, P.; Tarascon, J. M.; Laruelle, S. Deciphering the Multi-Step Degradation Mechanisms of Carbonate-Based Electrolyte in Li Batteries. J. Power Sources 2008, 178 (1), 409-421. https://doi.org/10.1016/j.jpowsour.2007.11.110.

(76) Michan, A. L.; Parimalam, B. S.; Leskes, M.; Kerber, R. N.; Yoon, T.; Grey, C. P.; Lucht, B. L. Fluoroethylene Carbonate and Vinylene Carbonate Reduction: Understanding Lithium-Ion Battery Electrolyte Additives and Solid Electrolyte Interphase Formation. Chem. Mater. 2016, 28 (22), 8149-8159. https://doi.org/10.1021/acs.chemmater.6b02282.

(77) William Walter Simons. The Sadtler Handbook of Proton NMR Spectra; Sadtler Research Laboratories, 1978.

(78) Rubinson, K. A.; Rubinson, J. F. Chapter 11, Nuclear Magnetic Resonance Spectrometry. In Contemporary instrumental analysis; Prentice Hall: Upper Saddle River, New Jersey 07458, 2000; p 840.

(79) Satterlee, J. D. Fundamental Concepts of NMR in Paramagnetic Systems. Part II: Relaxation Effects. Concepts Magn. Reson. 1990, 2 (3), 119-129. https://doi.org/10.1002/cmr.1820020302.

(80) Leanza, D.; Vaz, C. A. F.; Melinte, G.; Mu, X.; Novák, P.; El Kazzi, M. Revealing the Dual Surface Reactions on a HE-NCM Li-Ion Battery Cathode and Their Impact on the Surface Chemistry of the Counter Electrode. ACS Appl. Mater. Interfaces 2019. https://doi.org/10.1021/acsami.8b19511.

(81) Parimalam, B. S.; MacIntosh, A. D.; Kadam, R.; Lucht, B. L. Decomposition Reactions of Anode Solid Electrolyte Interphase (SEI) Components with LiPF6. J. Phys. Chem. C 2017, 121 (41), 22733-22738. https://doi.org/10.1021/acs.jpcc.7b08433.

(82) Wiemers-Meyer, S.; Winter, M.; Nowak, S. Mechanistic Insights into Lithium Ion Battery Electrolyte Degradation-a Quantitative NMR Study. Physical Chemistry Chemical Physics. Royal Society of Chemistry September 29, 2016, pp 26595-26601. https://doi.org/10.1039/c6cp05276b. 
(83) Plakhotnyk, A. V.; Ernst, L.; Schmutzler, R. Hydrolysis in the System $\mathrm{LiPF}_{6}$ - Propylene Carbonate - Dimethyl Carbonate - $\mathrm{H}_{2} \mathrm{O}$. J. Fluor. Chem. 2005, 126 (1), 27-31. https://doi.org/10.1016/j.jfluchem.2004.09.027.

(84) Li, Q.; Yan, S.; Yang, W. Interfacial Properties in Energy Storage Systems Studied by Soft XRay Absorption Spectroscopy and Resonant Inelastic x-Ray Scattering. Journal of Chemical Physics. 2020, p 140901. https://doi.org/10.1063/5.0003311.

(85) Augustsson, A.; Herstedt, M.; Guo, J. H.; Edström, K.; Zhuang, G. V; Ross, P. N.; Rubensson, J. E.; Nordgren, J. Solid Electrolyte Interphase on Graphite Li-Ion Battery Anodes Studied by Soft X-Ray Spectroscopy. Phys. Chem. Chem. Phys. 2004, 6 (16), 4185-4189. https://doi.org/10.1039/b313434b.

(86) Williams, R. S.; Denley, D.; Shirley, D. A.; Stöhr, J. Soft X-Ray Absorption Spectroscopy. Electronic and Morphological Structure of Poly(Vinylidene Fluoride). J. Am. Chem. Soc. 1980, 102 (18), 5717-5723. https://doi.org/10.1021/ja00538a003.

(87) Fang, S.; Jackson, D.; Dreibelbis, M. L.; Kuech, T. F.; Hamers, R. J. Anode-Originated SEI Migration Contributes to Formation of Cathode-Electrolyte Interphase Layer. J. Power Sources 2018, 373, 184-192. https://doi.org/10.1016/j.jpowsour.2017.09.050.

(88) You, Y.; Celio, H.; Li, J.; Dolocan, A.; Manthiram, A. Modified High-Nickel Cathodes with Stable Surface Chemistry Against Ambient Air for Lithium-Ion Batteries. Angew. Chemie Int. Ed. 2018, 57 (22), 6480-6485. https://doi.org/10.1002/ANIE.201801533.

(89) Erickson, E. M.; Li, W.; Dolocan, A.; Manthiram, A. Insights into the Cathode-Electrolyte Interphases of High-Energy-Density Cathodes in Lithium-Ion Batteries. ACS Appl. Mater. Interfaces 2020, 12 (14), 16451-16461. https://doi.org/10.1021/acsami.0c00900.

\section{Table of Contents (TOC) Figure}

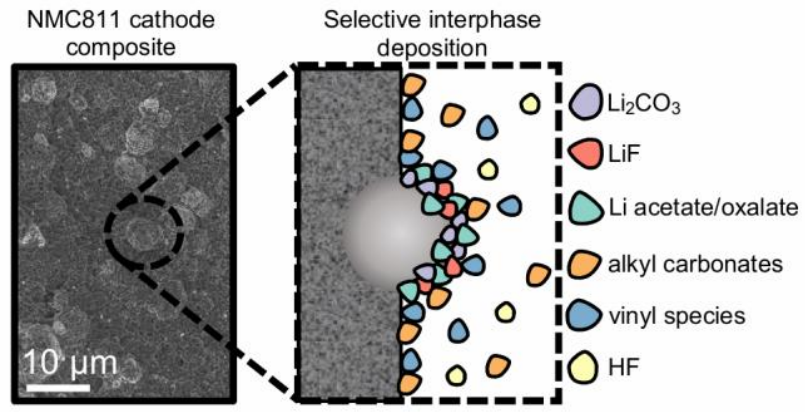

